\title{
Mix and match: organic and inorganic ions in the perovskite lattice
}

\author{
Julian Gebhardt and Andrew M. Rappe
}

October 8, 2018

\begin{abstract}
Modern materials science is evolving to a state where the composition and structure of a crystal can be controlled almost at will. Given that a composition meets basic requirements of stoichiometry, steric demands, and charge neutrality, researchers are now able to investigate a wide range of compounds theoretically and under various experimental conditions, selecting the constituting fragments of a crystal. One intriguing playground for such materials design is the perovskite structure. While a game of mixing and matching ions has been played successfully for about 150 years within the limits of inorganic compounds, the recent advances of organic-inorganic hybrid perovskite photovoltaics have triggered an intensified interest in analogous explorations including organic ions. Organic ions can, in principle, be incorporated on all sites of the perovskite structure, leading to hybrid (double, triple, etc.) perovskites and inverse hybrid perovskites. In fact, examples for each of these cases are known, including one up to all three sites occupied by organic molecules per $A B X_{3}$ unit. While this change from monatomic ions to molecular species is accompanied with increased complexity, it shows that concepts from traditional inorganic perovskites are transferable to the novel hybrid materials. The increased compositional space holds promising new possibilities and applications for the universe of perovskite materials. Here, we review the development of this field of hybrid materials since its beginning and the recent explorations of the novel structural and compositional members of the hybrid perovskite class.
\end{abstract}

\section{Contents}

1 Introduction $\mathbf{2}$

1.1 Effective ionic radii and Structural Descriptors . . . . . . . . 5

2 Hybrid perovskites $\quad 8$

2.1 Organic A-site: $\mathrm{HP}(\mathrm{A}) \ldots \ldots \ldots . \ldots . \ldots . \ldots$

2.2 Organic X-site: $\mathrm{HP}(\mathrm{X}) \ldots \ldots \ldots \ldots$

3 Perovskites with more than one organic ion $\quad 17$

3.1 Organic A- and X-sites: $\mathrm{HP}(\mathrm{AX}) \ldots \ldots . \ldots 18$

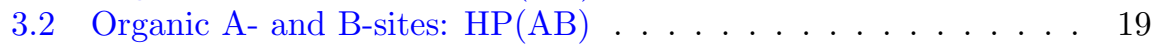

3.3 Organic Perovskites: OP . . . . . . . . . . . . . . 19 
6 Acknowledgement 22

\section{Introduction}

The perovskite crystal structure has proven to be one of the most fruitful structural platforms for functional materials.[1-18] Perovskites are materials with stoichiometry $A B X_{3}$ that crystallize in the well-known structure named for crystallographer Lev Perovski.[19] $A, B$, and $X$ stand for ionic groups, which are arranged as shown in Fig. 1 . In a cubic unit cell centered around an $A$-type ion, $B$-type ions occupy the corners, with $X$-type ions at the centers of all unit cell edges. This provides octahedral coordination of every $B$-site $\left(B X_{6}\right)$ and cuboctahedral coordination on the $A$-site $\left(A X_{12}\right)$. Many variations of $A-, B$-, and $X$-site anions are possible, with only two general requirements that must be fulfilled: (i) charge neutrality in the $A B X_{3}$ unit (typically, $X$ is a divalent or monovalent anion, hence $A$ and $B$ cations with oxidation states between +1 and +5 can be combined) and (ii) the ionic radii of the chosen composition must allow the above coordination, or different phases become more stable. Both of these simple design rules have a certain flexibility.

The electronic argument (i) can be stretched by allowing the combination of multiple $A B X_{3}$ units to form an overall charge neutral unit. For example, this is the case when considering $A_{2} B B^{\prime} X_{6}$ or $A A^{\prime} B_{2} X_{6}$ systems. Such double perovskite systems are known with $B$ and $B^{\prime}\left(A\right.$ and $\left.A^{\prime}\right)$ being the same elemental species (disproportion in oxidation state, e.g., $\mathrm{Cs}_{2} \mathrm{Au}^{+} \mathrm{Au}^{3+} \mathrm{I}_{6}$ ) [20] or different ones (e.g., $\mathrm{SrBaTi}_{2} \mathrm{O}_{6}[21]$ and $\mathrm{SrPbTi}_{2} \mathrm{O}_{6}$ [22] for $A$-site disproportion or $\mathrm{K}_{2} \mathrm{NbTaO}_{6}[23]$ and $\mathrm{Bi}_{2} \mathrm{FeCrO}_{6}[24]$ for the $B$-site). Of course, this concept can also be used to combine three $A B X_{3}$ units (e.g, $\left(\mathrm{CaTiO}_{3}\right)_{n}\left(\mathrm{SrTiO}_{3}\right)_{l}\left(\mathrm{BaTiO}_{3}\right)_{m}[25-$ $27])$ and much more complex stoichiometries with mixed ratios (e.g., $\left(\mathrm{Pb}_{2} \mathrm{InNbO}_{6}\right)_{3 / 4}\left(\mathrm{Ba}_{2} \mathrm{InBiO}_{6}\right)_{1 / 4}[28]$ or $\left.\left.\left[\mathrm{CaMn}_{3}^{3+}\right]\left[\mathrm{Mn}_{3}^{3+} \mathrm{Mn}^{4+}\right] \mathrm{O}_{12}\right][29]\right)$. Furthermore, although the bonding character in oxide perovskites is often mainly ionic, some compositions have an increased level of covalency (e.g., halides, sulfides, Bi- and Pb-based oxide perovskites). Thus, the electronic shell configuration and other effects like the steric demands of a metal lone-pair will influence the structure and stability of $A B X_{3}$ perovskite compounds.

In addition, the geometric argument (ii) allows for some flexibility. For a perfectly cubic perovskite, the (effective) ionic radii $r$ must fulfill the relation of Goldschmidt's tolerance factor $t=\frac{r_{A}+r_{X}}{\sqrt{2}\left(r_{B}+r_{X}\right)}=1$. [30, 31] However, perovskites can exist also with $t$ being not ideal, usually in a range of about $0.75<t<1.05$. [8] Whenever $t \neq 1$, the crystal distorts from an ideal cubic lattice, usually in form of off-center displacements, octahedral rotations, or a combination of both. The classification of Glazer[32, 33] can be used to describe such distortions from a perfectly cubic perovskite.[34] It is further possible that $A B X_{3}$ compounds are stable whose $t$ does not fall into the interval that is required for the perovskite crystal structure. In these cases that are no longer stabilized by deformations and tilting, one observes other phases where 
the connectivity of $B X_{6}$ octahedrons is changed from the corner-sharing perovskite structure to the edge-sharing $\mathrm{NH}_{4} \mathrm{CdCl}_{3}$ phase,[35] the mixed corner and edge-sharing $\mathrm{CaIrO}_{3}$ phase,[36] or a variety of other phases including facesharing and mixed octahedral connectivity. [37, 38] Within these electronic and structural limits, a huge variety of compositions can be formed, with many interesting physical phenomena, all related to the elemental composition of the $A B X_{3}$ network and the resulting electronic and geometric structures.

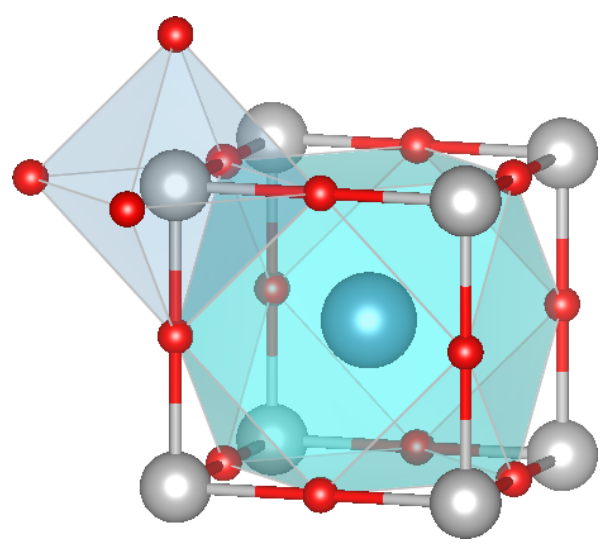

Figure 1: Perovskite structure for the prototypical $\mathrm{CaTiO}_{3}$. Ions are displayed $A=\mathrm{Ca}^{2+}$ (ice blue), $B=\mathrm{Ti}^{4+}$ (silver), and $X=\mathrm{O}^{2-}$ (red). Cationic species are surrounded by $B X_{6}$ octahedral and $A X_{12}$ cuboctahedral oxygen coordination, displayed as light blue or cyan polyhedron, respectively.

Since their discovery in 1839 , perovskites traditionally have been inorganic compounds, i.e., in most compounds $A, B$, and $X$ ions have been inorganic, and mostly monoatomic ions. The vast majority of naturally discovered inorganic compounds have cations on the $A$ - and $B$-site and a mono- or divalent anion on the $X$-site. Hence, more recently discovered materials with anions on the $A$ and $B$-site and a cation on the $X$-site were denoted inverse or anti perovskites (IP), to take into account this inversion of the commonly-accepted charge states in the perovskite lattice. The first reports of such compounds seem to be work on carbides and nitrides by Haschke[39] and others slightly afterwards.[40, 41] Although newer than traditional perovskites, they also show a large variety with respect to composition and physical properties.[42-51]

Despite a clear focus on inorganic materials, compounds with $A B X_{3}$ stoichiometry that included organic molecules also date back to the late 19 th century. $[52,53]$ These initial works with ammonia on the $A$-site have been ironically been carried out already for lead halides. The history of compounds employing undoubtedly organic groups can be traced back to at least the thesis of Raagland in 1897.[54] In his work on cadmium halide compounds he employed methylammonium $\left(\mathrm{CH}_{3} \mathrm{NH}_{3}^{+}, \mathrm{MA}\right)$, dimethylammonium $\left(\left(\mathrm{CH}_{3}\right)_{2} \mathrm{NH}_{2}^{+}, \mathrm{M}_{2} \mathrm{~A}\right)$, and triethylammonium $\left(\left(\mathrm{CH}_{3}\right)_{3} \mathrm{NH}^{+}, \mathrm{M}_{3} \mathrm{~A}\right)$ (see Fig. 2 for details on organic cations). Of course, these early studies were limited by the time and viewed them as salts with no direct link to perovskites.

To this early history one can also trace back related compounds with usually larger organic groups and varying stoichiometry.[55, 56] Some of these 
compounds that were investigated over time had $A_{2} B X_{4}$ stoichiometry. [54-58] Crystals with such stoichiometry were later classified by Ruddlesden and Popper (RP)[59] and shown to have an $A$-site double layer. These findings can be related to the perovskite structure by the realization that the larger $A$-site does not fit into the $B X_{3}$ cage. If the steric demand of the $A$-site cation is increased in only one direction, the $B X_{3}$ backbone is broken along this (stacking) direction, keeping the corner sharing connectivity of $B X_{6}$ octahedrons along the perpendicular plane. Such a structure was shown for HPs in the work by Steadman in 1970,[60] and the early work on these compounds was reviewed by Arend.[61]

By combining such large $A$-site cations with small cations $\left(A^{\prime}\right)$ that fit into the $B X_{6}$ pocket along all directions, a whole family of $A_{2} A_{(n-1)}^{\prime} B_{n} X_{(3 n+1)}$ compounds is formed. Due to the connection of such systems with perovskites (for the limiting case $n=\infty$ ) and the fact that in these phases $n$ perovskite layers are detached from one another,[62] RP compounds are also known as layered perovskites. Of course, the steric demands of an $A$-site ion may exceed the capabilities of the $B X_{3}$ network not only in one direction. For a RP phase, the anchoring groups must fit at least into the rectangle spanned by the terminal $X$-sites. In that case, structural alteration from the $3 \mathrm{D}$ perovskite structure due to too large $A$-sites do not only occur by cutting along the $\langle 100\rangle$ direction. Structures are also known that can be related to bulk perovskite by detaching layers along the $\langle 110\rangle$ direction (leading to $A_{2} A_{n}^{\prime} B_{n} X_{3 n+2}$ stoichiometry) or the $\langle 111\rangle$ direction (leading to $A_{2} A_{n-1}^{\prime} B_{n} X_{3 n+3}$ stoichiometry), respectively. [63] Although this variation is intriguing on its own, we will not discuss such systems here further, noting that they have been recently reviewed.[63-65]

A similar clear connection between salts with mixed organic and inorganic ions in an $A B X_{3}$ stoichiometry to the atomistic structure of inorganic perovskites can be traced back to 1978.[66] In recent years, this class of (MA) $B X_{3}$ $(B=$ Sn and $\mathrm{Pb})$ halide $(X=\mathrm{Br}, \mathrm{Cl}$, and $\mathrm{I})$ compounds has been demonstrated to perform exceptionally well in single-junction photovoltaic $(\mathrm{PV})$ devices, with efficiencies up to $23.3 \%$ [67]. These developments had two major implications, important enough to coin this new addition to the compositional space of perovskites as hybrid organic inorganic perovskite (HOIP, note that we will use the simplified abbreviation hybrid perovskite (HP) instead, since the context of hybrid is inherently clear. This name could go back to Azumi and co-workers who termed a layered variant as inorganic-organic hybrid material.)[68]: 1. The introduction of organic molecules adds a whole new group of ions that can be incorporated into perovskites, which enter a new realm of radii that can be significantly larger than any (monoatomic) inorganic ion. 2. The exceptional $\mathrm{PV}$ performance and easy fabrication of (MA) $\mathrm{Pb} X_{3}$ compounds is accompanied by drawbacks that are almost as astonishing. [69] That is, (MA) $\mathrm{Pb} X_{3}$-based $\mathrm{PV}$ devices are not only problematic in terms of their lead content, but are also susceptible to moisture, air, and illumination; properties hardly compatible with efficient and profitable PVs. In combination, these two findings have led to a surge in HP research, focusing on understanding the intriguing properties of (MA) $\mathrm{Pb} X_{3}$ compounds and exploring different compositions employing various organic and inorganic ions. Various properties of HPs have been intensively reviewed recently.[70-80] The HP materials search is partly, but by no means exclusively, driven by the goal to replace (MA) $\mathrm{Pb} X_{3}$ with similar compounds that share their strengths but not their weaknesses.[63, 81, 82] 
Here, we focus on the variety of compounds that can be formed by mixing organic with inorganic ions in an $A B X_{3}$ stoichiometry, focusing on materials search within the defined electronic and structural limits of the perovskite crystal structure.

\subsection{Effective ionic radii and Structural Descriptors}

As highlighted above, the ions of an $A B X_{3}$ composite must not only be chosen to be charge neutral but should also have a reasonable tolerance factor. In order to evaluate the latter, effective ionic radii $r_{\text {ionic }}$ of all containing ions are required. Since the latter are known to depend on the oxidation state (OS) and coordination number $(\mathrm{CN})$, these dependencies should also be known, in particular the radii of all ions in the expected OS with $\mathrm{CN}=12$ ( $A$-site), $\mathrm{CN}=6$ ( $B$-site), and $\mathrm{CN}=2(X$-site). Establishing such radii would require a rigorous definition of ions in solids, i.e., a clear local assignment of charge to atomic cores. Although there exist several useful approximative schemes for localized charges,[83-86] these partitioning schemes do not follow a general underlying quantum mechanical observable and remain somewhat arbitrary (this is not withstanding a method that allows the assignment of integer oxidation states to ions in insulating systems based on Born effective charges).[87] Despite this difficulty, effective ionic radii can be approximated empirically, a field dating back to the early works of Landé and others in the early 20th century. [30, 8893] Over time, reasonable definitions have been found that allowed to establish many of the required effective ionic radii for most elements (and, thus, monoatomic inorganic cations) with useful accuracy. Most widely used is the approach of Shannon and Prewitt (SP), [94, 95] who constructed a rather comprehensive list of ionic radii from interatomic distances after defining ionic radii for two anions $\left(\mathrm{O}^{2-}\right.$ and $\left.\mathrm{F}^{-}\right)$. Further modifications of this principle to take into account different anionic references exist but are less widely used; [96, 97] however, the importance of this dependence has been recently outlined with respect to HPs. [98] Although approximate, the concept of $t$ based on SP radii has been very successful in estimating the stability of inorganic perovskites.

To apply this principle also to HPs, effective ionic radii must also be established for organic cations. A first useful empirical attempt to do so was provided by Kiesslich et al.[99], based on bond distances within the organic molecule and SP ionic radii for the (cationic) end groups $\left(\mathrm{NH}_{3}^{+}\right)$. The approach yielded ionic radii (e.g., $2.17 \AA$ for MA) that were tested with some success on 2352 compounds.[100]

A shortcoming of this approach is the large number of hypothetical cases without experimental confirmation, i.e., the small number of successfully synthesized HPs. While this approach seems to have provided a good initial estimate, it has some conceptual concerns: Modeling an $\mathrm{NH}_{3}^{+}$group and its noncovalent interactions to the $B X_{3}$ network as an $N^{3-}$ ion seems fairly drastic, and further evaluation of how this and other factors (orientation, bonding partner ( $X$ and $B)$, temperature, etc.) affect the results is necessary.

Concurrently, Filip and co-workers used density-functional theory (DFT) to determine effective ionic radii (in their words "steric radii") for their investigation of $A \mathrm{PbI}_{3}$ compounds.[101] Twenty-two cations were considered in total, 18 of which lead to hypothetical compounds. Since there is no ab initio definition of ionic radius, they chose the sphere enclosing $95 \%$ of the electron density 
as effective ionic radius. Such an ad-hoc definition is common practice due to the lack of a rigorous alternative but remains arbitrary. Furthermore, technical difficulties arising when performing such calculations on charged molecules in periodic implementations were ignored; hence, the resulting values (e.g., $2.03 \AA$ for MA) should perhaps be seen as rough estimates. This is also apparent by the significant underestimation of the SP effective radii for the included alkali metals (from Cs to Na: underestimation of $r_{\text {ionic }}$ by 5.9 - 38.8\%). Nevertheless, Filip and co-workers raised an important point - the hydrogen bonding that dominates in HPs should potentially not be compared 1-to-1 with the ionic bonding in traditional perovskites. It must certainly be viewed as a different interaction with much more complicated directional dependence and possibly very different behavior with respect to the bond species.

Becker et al.[102] undertook another attempt to define effective ionic radii for organic molecules from electronic structure theory. These authors evaluated radii for 18 organic cations. In short, they use once more the electron density, defining the ionic radius as that sphere, where the density $\varrho(A)$ of a given cation $A$ falls off to a particular value of the reference case (the density of an isolated $\mathrm{NH}_{4}^{+}$cation). By choosing the particular density value for such a comparison, naturally, empiricism enters their ab initio model, since no exact threshold exists. Instead of a fixed percentage like Filip, a cutoff iso-density value was chosen in a way that the computed reference density $\varrho\left(\mathrm{NH}_{4}^{+}\right)$represents the effective ionic radius of the $\mathrm{NH}_{4}^{+}$ion in 12 -fold coordination. The latter, was chosen from experiments.[103] Doing so one introduces empiricism and ambiguities such as the heavy dependence of the reference radii on SP values, the dependence of $r_{\text {ionic }}\left(\mathrm{NH}_{4}^{+}\right)$on $B$ and $X$ in the $\left(\mathrm{NH}_{4}\right)_{2} B X_{6}$ compounds, temperature, etc. Overall, the authors of the experimental reference value $r_{\text {ionic }}\left(\mathrm{NH}_{4}^{+}\right)$ only trust it as a rough estimate, noting "In general, the radius will vary, for a given C.N., with the extent of hydrogen bonding and no single fixed value can be given.". For these reasons and by relying on a coarse experimental value to high accuracy (three decimal places), also this approach remains ambiguous, although all calculations were carried out with care and on the same footing.

In any case, the presented model arrives, yet again, at reasonable values (e.g., $2.38 \AA$ for MA). For $88 \%$ of the experimentally confirmed 40 compounds (out of a larger set of 486 permutations, combining the 18 organic cations with nine divalent metals and $X=\mathrm{Cl}, \mathrm{Br}, \mathrm{I})$, structural factors ( $t$ and $\mu$, see below) result that fall into the established region for stable perovskites. In the latter step, the rescaling of $\mathrm{SP}$ radii when dealing with $X \neq \mathrm{O}, \mathrm{F}$ by Travis[98] was employed.

In summary, the recent literature suggests a wide range of $2.03 \AA \leq r(\mathrm{MA}) \leq$ $2.38 \AA$ based on systematic ionic radius approaches. This, however, should not be discouraging nor should the above be seen as criticism of these studies. It is solely a reminder that ionic radii are never exact. As has become evident from the discussion above, radius estimates will improve over time as the amount of reliable structural data increases. This will also enable the application of a modern data harvesting approach to this problem that we have proposed recently.[104] All that is clear by now is that new ionic radiuss protocols should include the dependence of $r_{\text {ionic }}(X[\mathrm{OS}, \mathrm{CN}, Y, T])$ on the OS, [95] CN, [95], partnering halide $(Y),[98]$, and temperature.[105]

Once $r_{\text {ionic }}$ is chosen, one can evaluate $t$ in order to predict the likelihood of a given composition of ions to form the perovskite structure. While exact 
thresholds depend on the specific perovskite class (e.g., the $X$-site anion) and will evolve a bit over time with the approximations for $r_{\text {ionic }}$, values of $0.75<$ $t \leq 1$ should be targeted. Smaller values of $t$ are likely to favor other phases with corner-, edge-, and face-sharing $B X_{6}$ octahedra, whereas larger values of $t$ often form hexagonal perovskites.[106, 107] Although such structures can be equally fascinating, we will here focus on a strict definition of perovskites, meaning materials that crystalize in the perovskite structure rather than other structures with $A B X_{3}$ stoichiometry. Compositions above the lower bound but smaller than $t=1$ are likely to exist but with distortions. This can be the traditional ionic displacements and octahedral rotations $[8,32,33,108]$ or tilting of non-spherical molecular ions.[109]

Moving beyond only considering $t$, structural chemists realized that both radii $r_{A}$ and $r_{B}$ affect the phase of a particular material $A B X_{3}$ (for a given $X$ ). In the area of inorganic perovskites, pioneering work was performed by Muller and Roy,[110] organizing observed ternary material structural phases into structural maps in terms of $A$ and $B$ ionic radii and coordination for $A B X_{3}$ with $X=\mathrm{O}, \mathrm{F}$, and $\mathrm{Cl}$. Later, Pettifor analyzed the structure and coordination of materials based on grouping atoms into classes that tracked with electronegativity.[111] The resulting structure map for $A B \mathrm{~S}_{3}$ materials[112] did not offer full predictive capability based on these atomic parameters. Brehm et al. generalized this approach by modifying the tolerance factor with electronegativity to provide clean separation between corner- (perovskite), edge-, and face-sharing structures.[37]

Recently, this type of multi-dimensional structure classification has been applied to hybrid perovskites. In addition to $t$, the ratio between $B$ - and $X$-site ionic radii has been suggested as additional structural criterion. This octahedral factor $\mu=\frac{r(B)}{r(X)}[113]$, is a measure for how well the $B$-site ions fit within the $X$-site octahedra. Assuming hard spheres in an ideally packed octahedron (touching spheres), one finds a ratio of $\mu=0.41$.[114] Larger values are acceptable, simply meaning that neighboring $X$-sites do not touch. However, smaller ratios indicate that the $B$-site ion is too small, leading either to off-center displacement or requiring neighboring $X$-site anions to overlap. This suggests a lower bound for perovskites; these have been established empirically for oxides $(\mu>0.425),[113]$ halides $(\mu>0.442),[115]$ and HPs $(\mu>0.41) .[98]$ Thus, considering $\mu$ in addition to $t$, when mixing ions to form novel compounds appears advisable.

Very recently, it was further suggested to combine both factors $(t$ and $\mu)$ and also take into account the atomic packing fraction as $\nu=\frac{V(A)+V(B)+3 V(X)}{V}$, evaluating the ratio of ionic volumes $V(i)$ to the unit cell volume $V$.[7] Assuming again hard spheres, a larger ratio should increase the likelihood of structural integrity. It is indeed found that fitting formation energies with respect to a combined structural factor term $(t+\mu)^{\nu}$ increases the accuracy for HPs.

A complementary strategy for assessing perovskite stability is to evaluate the bond length alternation within the octahedra, i.e., the difference $\Delta$ of $B-X$ bond lengths. Since perovskites such as $\mathrm{CsPbI}_{3}[116]$ usually show a small variation, compositions that prefer different (non-perovskite) coordination can be indicated by excessive bond length differences. However, one must be careful not to choose too tight a threshold. In order not to discard stable structures that show off-center displacements on the $B$-site, a value of $\Delta=0.5 \AA$ was sug- 
gested by Filip et al.[116] for their computational screening of HP composition. In any case, such a structural descriptor is only useful to analyze and categorize compounds once the measured or computed structure is known, not as a predictive tool.

Finally, the same authors combined a variety of limiting cases in order to define a stability range in the $t$ and $\mu$ space (and an additional octahedral difference parameter for double perovskites) purely based on thresholds that are not determined phenomenologically.[117] This approach was then used to classify known (inorganic) perovskite and non-perovskite structures as well as to determine all ion combinations that, in principle, should form inorganic perovskites. The large amount of about 100.000 unknown, feasible structures indicate the sheer infinite possibilities that can be envisioned once organic molecules are added into the mix.

\section{$2 \quad$ Hybrid perovskites}

We consider HPs to be all inorganic-organic hybrid materials (at least one organic ion) in the (pseudo) cubic perovskite structure. There is no restriction of the site that the organic ion may occupy. The only restriction is that the larger of two ions of the same type (cations for perovskites, anions for inverse perovskites) ought to occupy the $A$-site. Even with the largest (monoatomic) inorganic ions and the smallest possible organic cations, this means that organic ions can only be employed on the $A$ - and $X$-sites. Furthermore, only a limited set of organic ions will fit sterically on the sites of such perovskite structures. For the remainder of the manuscript, we will adopt a notation of denoting the site(s) that organic ions occupy in parenthesis after the respective type of perovskite. Note, that the above statement deliberately excludes larger inorganic ions or small charged clusters that potentially could be employed analogously to metal-organic frameworks (MOF), which then would easily allow $B$-site organic ions.[118-120]

\subsection{Organic A-site: $\mathrm{HP}(\mathrm{A})$}

As mentioned in the introduction, while the history of HPs dates back to the late 19th century, the atomistic crystal structure and a connection to perovskites was drawn by Weber in 1978 by studying (MA) $\operatorname{SnBr}_{x} \mathrm{I}_{3-x}(x=0-3)$ as "compounds [that] show intense color and conducting property".[66] Shortly afterwards, (MA) $\mathrm{PbX}_{3}$ compounds were characterized as "compounds [that] show intense color, but $[. .$.$] no significant conductivity under normal conditions"$ in a seminal work that is often quoted as starting point for HP research.[121] In both initial reports, Weber already correctly established the correlation to $\operatorname{Cs} B X_{3}$ compounds, their dissolution in water and methanol, and their color as indication for light absorption and an inner photoelectric effect in relation to $\mathrm{CsPb}_{3}$.[122] However, his initial measurements for the tin compounds showed metallic behavior, leading to a slight misinterpretation, although noting in both cases that further analysis of the photo conductance is required.

Webers original work on Sn appears to have not been actively pursued at first, despite occasional works on HPs employing other metals[123, 124] and layered structures, e.g., by Couzi and co-workers[125] (the earliest citation of 
Weber's Sn work as indexed by Scopus is found in 2004). However, spearheaded by Mitzi[126], researchers extended Webers work on $\mathrm{Pb}$ compounds in the 1990s. Investigating mainly iodides including MA and formamidinium $\left(\mathrm{CH}\left(\mathrm{NH}_{2}\right)_{2}^{+}, \mathrm{FAd}\right)$ on the $A$-site and $\mathrm{Pb}, \mathrm{Sn}$, and to a lesser extent $\mathrm{Eu}, \mathrm{Yb}$, and $\mathrm{Ca}$ on the $B$-site. Their focus, however, was not yet on photovoltaics, and the compositional space was mainly explored with respect to the $A$-site. Since only the smallest organic ions fit into the perovskite backbone (here spanned by the $\mathrm{Pb} I_{3}$ network), this naturally leads to too large $A$-site organic cations and, therefore, the structural transition to RP structures. It was not until Kojima's work on (MA) $\mathrm{PbI}_{3}$ in 2009,[127] when the first HP-based solar cell was reported with an efficiency of $3.8 \%$ (although the idea circled the scientific community slightly earlier, see a recent review for a historical survey[78]). This initial report was followed by a rapid improvement of the MA solar cell, including the work by $\operatorname{Im}(6.5 \%)[128$ ], up to record efficiencies of 20.9 [129] to $23.3 \%$.[67] In parallel, FAd was then employed with increasing success,[130] whereas recently some additional efficiency increase was achieved by using mixtures and tandem cells (see [78, 129] and references therein as well as [67], 25.2\% highest confirmed value according to [129]; recently a value of 27.3 was reported\%[131]).

Research on Sn-based HPs accelerated more recently, motivated by the search for Pb-free PV materials. Correcting Weber's initial claim of metallic character[132], in 2014 Hao and co-workers published a series of papers[133, $134]$ reporting for the first time on PV devices based on pure (MA) Sn $X_{3}$ halides. Shortly afterwards, the current leader (6.4\% efficiency) was reported.[135] Thus, replacing tin with lead leads so far to a drastic reduction of the solar efficiency, and tin appears promising only as a supplement in mixed materials or tandem cells. See [136] for a recent review about the development of $A \operatorname{Sn} X_{3}$ solar cells.

In summary, this brief history of time shows: (i) Weber already discussed many key points of lead-halide HPs from today's perspective, (ii) it took 31 years after Weber until the first publication of a HP solar cell, (iii) the rise this technology has seen ever since is uncanny, and (iv) MA, FAd, and Cs (which we did not include but which, due to its status of largest monoatomic cation, frames the path of HP PVs) lead or tin halides show remarkable promise, have been intensively studied, but are also seriously flawed. This triggered more recently a surge of research efforts looking for more stable and/or lead-free alternative materials, while retaining the properties of (MA/FAd) $\mathrm{Pb} X_{3}$. Increasingly, this compositional screening is driven by extensive electronic-structure calculations. While still focused on the three established $A$-site cations (MA, FAd, and Cs), $[116,137,138]$ recent efforts also resulted in a broader database.

Including 16 organic cations (see Fig. 2 for a list of monovalent cations) in their work, Kim and co-workers[139] investigate the compounds resulting from permutations of group XIV elements ( $\mathrm{Ge}, \mathrm{Sn}$, and $\mathrm{Pb}$ ) with halides (F, Cl, $\mathrm{Br}$, and I). Note that all structural motives are archived, i.e., including $A B X_{3}$ compounds that are structurally are no HPs.

When allowing one direction of the perovskite lattice to be significantly elongated, most of the investigated cations form perovskites (see Table 1 for the Ge compounds). Notable exceptions are hydroxylammonium $\left(\mathrm{HONH}_{3}^{+}, \mathrm{HOA}\right)$ and hydrazinium $\left(\mathrm{H}_{2} \mathrm{NNH}_{3}^{+}, \mathrm{HA}\right)$, which favor the related $\mathrm{CaIrO}_{3}$ phase for all halides. For some cations, the phase stability depends on the halide, i.e., ammonium $\left(\mathrm{NH}_{4}^{+}\right)$shows different corner-sharing phases with $\mathrm{Cl}$ than with $\mathrm{I}$. Interestingly, the results of Kim et al. suggest that $\left(\mathrm{NH}_{4}\right) \mathrm{GeBr}_{3}$ favors the 


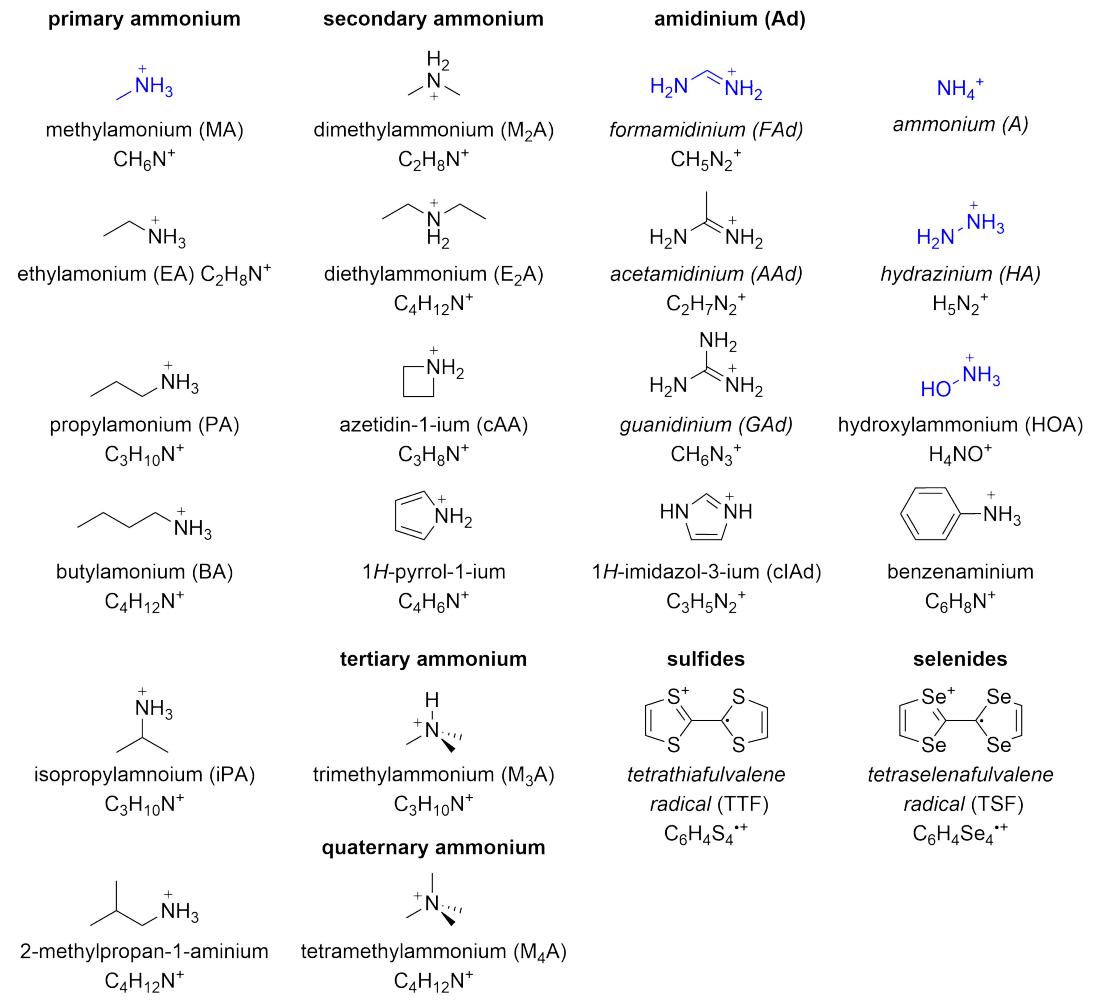

Figure 2: List of organic monovalent cations considered in $\operatorname{HP}(\mathrm{A})$ structures. Names printed in italics represent molecules that enable a symmetric bonding with multiple (mainly two) identical groups. Structures known to be suitable for the formation of 3D perovskites are blue. 
perovskite structure again, which indicates that the flat potential energy surfaces of these compounds do not always allow a simple differentiation of phases by atomization energies or periodic trends. Furthermore, we note that in this work no comparison to other stoichiometries is made. This means, that the current version of this database does not determine whether a specific composition is stable as perovskite or, e.g., prefer a transition to a layered RP phase. Some indication of phase (in)stability can be deduced from the observed strong distortions of some compounds with large cations.

In general, a survey of currently known examples of RP phases and hexagonal $\mathrm{HP}(\mathrm{A}) \mathrm{s}$ provides the following perspective on the size requirements of proposed organic cations: For simple alkyl chains, only MA (C1) is known to form 3D perovskite, whereas ethylammonium $\left(\mathrm{CH}_{3} \mathrm{CH}_{2} \mathrm{NH}_{3}^{+}, \mathrm{EA}\right)(\mathrm{C} 2)$ forms a hexagonal perovskite.[140] Larger chains are known to form 2D RP phases, e.g., Y$\mathrm{CH}_{2} \mathrm{CH}_{2} \mathrm{NH}_{3}^{+}(\mathrm{Y}=\mathrm{Cl}, \mathrm{Br}, \mathrm{OH}, \mathrm{CN})$ analogs to $\mathrm{C} 3$ chain length (see references in [63]) or butylammonium (C4).[141] This means, however, that all secondary or higher ammonium cations are also too large for the $A$-site pocket (the size of a $\mathrm{PbI}_{3}$ backbone).

For the amidiniums, again FAd is the only known $3 \mathrm{D} \mathrm{Pb}$ or $\mathrm{Sn}$ halide $\mathrm{HP}(\mathrm{A})$. Larger cations obtained by replacing the hydrogen at the central carbon by larger groups (e.g., acetamidinium $\left(\mathrm{H}_{3} \mathrm{CC}\left(\mathrm{NH}_{2}\right)_{2}^{+}\right.$, AAd) or guanidinium $\left.\left(\mathrm{C}\left(\mathrm{NH}_{2}\right)_{3}^{+}, \mathrm{GAd}\right)\right)$ lead to $\langle 110\rangle$ oriented layered perovskites $(\mathrm{GAd})_{2} \mathrm{PbI}_{4}$ and $\left[\mathrm{IC}\left(\mathrm{NH}_{2}\right)_{2}\right]_{2} \mathrm{PbI}_{4},[63]$ apparently limiting this class of organic cations to the one known example for $3 \mathrm{D}$ perovskites. This analysis is also mostly in line with the ionic radii in Ref.[99] Only the acetamidinium radius is predicted to be slightly smaller than formamidinium, indicating that not all aspects of the steric demands of nonspherical organic cations are accounted for correctly by this scheme. Although it is, of course, possible that borderline cases may allow the coexistence of $3 \mathrm{D}$ and $2 \mathrm{D}$ phases by optimized reaction conditions or advanced fabrication techniques, $[142,143]$ it is likely that almost all organic cations other than A, MA, FAd, HA, and HOA are unsuitable to form 3D perovskites, unless the $A$-site pocket is increased (methods to do so are discussed below). This should always be considered during computational screening and the design of new HP materials in general.

One major drawback of (MA) $\mathrm{Pb} X_{3}$ compounds is the toxicity of lead.[144] The goal of replacing it with less toxic elements for wide-spread PV applications will definitely require to continue investigations of a wide variety of compositions. Another key issue with these materials is their low stability with respect to environmental exposure. This instability may be solvable via materials design or at higher levels, such as device engineering or coating.[145, 146] Thus, most research addressing further variation of the $A B X_{3}$ composition (besides the screening for $A$-site organic molecules and combinations of halides discussed above) is focused on replacing $B$-site lead with other elements.

Beyond isoelectronic substitution of $\mathrm{Pb}$, prime candidates include alkalineearth metals and the first two rows of transition metals other than group III, all of which are known to adopt $\mathrm{OS}=+2$. The $5 d$ transition metals might be considered as well, although here usually higher OS are favored. Last but not least one might even introduce metals in different OS, e.g., +1 (group XIII) and +3 (group XV). Note, however, that when introducing other heavy metals, the question of their toxicity arises. For example, $\mathrm{Tl}^{+}$is at least as problematic as $\mathrm{Pb}^{2+}$ salts.[147] $\mathrm{Bi}^{3+}$ is an improvement over lead, but still not free of poten- 


\begin{tabular}{|c|c|c|}
\hline$A$ & $B$ & $X$ \\
\hline $\mathrm{CH}_{3} \mathrm{NH}_{3}^{+}(\mathrm{MA})$ & $\mathrm{Ge}$ & $\mathrm{F}, \mathrm{Cl}, \mathrm{Br}, \mathrm{I}$ \\
\hline $\mathrm{CH}_{3} \mathrm{CH}_{2} \mathrm{NH}_{3}^{+}(\mathrm{EA})$ & $\mathrm{Ge}$ & $\mathrm{F}, \mathrm{Cl}, \mathrm{Br}, \mathrm{I}$ \\
\hline $\mathrm{CH}_{3} \mathrm{CH}_{2} \mathrm{CH}_{2} \mathrm{NH}_{3}^{+}(\mathrm{PA})$ & $\mathrm{Ge}$ & $\mathrm{F}, \mathrm{Cl}, \mathrm{Br}, \mathrm{I}$ \\
\hline $\mathrm{CH}_{3} \mathrm{CH}_{2} \mathrm{CH}_{2} \mathrm{CH}_{2} \mathrm{NH}_{3}^{+}(\mathrm{BA})$ & Ge & $\mathrm{F}, \mathrm{Cl}, \mathrm{Br}, \mathrm{I}$ \\
\hline$\left(\mathrm{CH}_{3}\right)_{2} \mathrm{CH}_{2} \mathrm{NH}_{3}^{+}(\mathrm{iPA})$ & Ge & $\mathrm{F}, \mathrm{Cl}, \mathrm{Br}, \mathrm{I}$ \\
\hline$\left(\mathrm{CH}_{3}\right)_{2} \mathrm{NH}_{2}^{+}\left(\mathrm{M}_{2} \mathrm{~A}\right)$ & Ge & $\mathrm{F}, \mathrm{Cl}, \mathrm{Br}, \mathrm{I}$ \\
\hline $\mathrm{CH}_{2} \mathrm{CH}_{2} \mathrm{CH}_{2} \mathrm{NH}_{2}^{+}$(cAA) & Ge & $\mathrm{F}, \mathrm{Cl}, \mathrm{Br}, \mathrm{I}$ \\
\hline$\left(\mathrm{CH}_{3}\right)_{3} \mathrm{NH}^{+}\left(\mathrm{M}_{3} \mathrm{~A}\right)$ & $\mathrm{Ge}$ & $\mathrm{F}, \mathrm{Cl}, \mathrm{Br}, \mathrm{I}$ \\
\hline$\left(\mathrm{CH}_{3}\right)_{4} \mathrm{~N}^{+}\left(\mathrm{M}_{4} \mathrm{~A}\right)$ & $\mathrm{Ge}$ & $\mathrm{F}, \mathrm{Cl}, \mathrm{Br}, \mathrm{I}$ \\
\hline $\mathrm{HC}\left(\mathrm{NH}_{2}\right)_{2}^{+}(\mathrm{FAd})$ & $\mathrm{Ge}$ & $\mathrm{F}, \mathrm{Cl}, \mathrm{Br}, \mathrm{I}$ \\
\hline $\mathrm{CH}_{3} \mathrm{C}\left(\mathrm{NH}_{2}\right)_{2}^{+}(\mathrm{AAd})$ & Ge & $\mathrm{F}, \mathrm{Cl}, \mathrm{Br}, \mathrm{I}$ \\
\hline $\mathrm{C}\left(\mathrm{NH}_{2}\right)_{3}^{+}(\mathrm{GAd})$ & $\mathrm{Ge}$ & $\mathrm{F}, \mathrm{Cl}$ \\
\hline $\mathrm{CHCHNH}_{2} \mathrm{CHNH}^{+}$(cIAd) & $\mathrm{Ge}$ & $\mathrm{F}, \mathrm{Cl}, \mathrm{Br}, \mathrm{I}$ \\
\hline $\mathrm{NH}_{4}^{+}$ & $\mathrm{Ge}$ & $\mathrm{F}, \mathrm{Br}$ \\
\hline
\end{tabular}

Table 1: $A B X_{3}$ compositions whose energetic minimum within the tested structural motifs by Kim et al.[139] corresponds to the perovskite structure (allowing heterogeneous bond length) for the example of $B=\mathrm{Ge}$. (HOA/HA) Ge $X_{3}$ are predicted to prefer other phases.

tial risks.[148] Furthermore, such modifications violate the neutrality principle in simple $A B X_{3}$ compounds and require double perovskites or more complex stoichiometry (see below).

A quite extensive screening of $B$-site cations in $\mathrm{HP}(\mathrm{A})$ structures was carried out by Filip and others.[116] Albeit using the inorganic $\mathrm{Cs}^{+}$on the $A$-site, the structural similarities between Cs and MA perovskites justifies drawing some insight from this study. A yet broader study considering $A=\mathrm{Cs}^{+}, \mathrm{MA}^{+}$, and $\mathrm{FAd}^{+}$was presented,[138] showing that the incorporation of Ge and Sn is successful from a structural design point of view. Even some examples with band gaps predicted to fall in an interesting range at least for tandem PV applications were found.[116, 139]

Among the alkaline-earth metals, $\mathrm{Be}^{2+}$ appears too small $\left(t>1\right.$ for $\mathrm{Cs}^{+}$ or $\mathrm{MA}^{+}$(using $2.17 \AA$ ) halides $X=\mathrm{Cl}, \mathrm{Br}$, and $\mathrm{I}$ ). $\mathrm{Mg}^{2+}$ also seems too small, at least in conjunction with MA, and also for $A=\mathrm{Cs}^{+}$it was confirmed that a corner-sharing non-perovskite phase is more stable.[116] However, here and in many cases the potential-energy surface for HPs seems to be very flat, with various accessible metastable phases (e.g., $\mathrm{CsPbI}_{3}$ ). Ca through Ba, however, yield tolerance factors that indicate that these compounds will favor the perovskite structure for ions comparable in size to Cs and MA. However, their band gap is predicted to be large and, hence, they receive limited attention when focusing on PV applications.[116]

The next group of possible +2 metals are transition metals. The largest +2 transition metal in six-fold coordination is titanium. [95] While the resulting tolerance factors suggest a perfect fit for $\mathrm{CsTi}_{3}$ perovskites, slightly larger organic ions (e.g., MA) are likely to be too large, which is also observed in screening studies.[116] The second row, however, holds with slightly larger ionic radii several promising prospects. According to computations, many of these 
compounds show metallic behavior, others are toxic $(\mathrm{Cd})$, excluding them from further investigations in recent studies, $[116,138]$ but they nevertheless, seem to be able to form $\mathrm{HP}(\mathrm{A}) \mathrm{s}$. Last but not least in the third row, one encounters many metals that prefer other oxidation states, requiring stoichiometric modifications. Possible for $\mathrm{HP}(\mathrm{A}) \mathrm{s}$ are $\mathrm{Pt}$ and $\mathrm{Hg}$, which, again have not gained much interest due to their metallic behavior $(\mathrm{Pt})$ or toxicity $(\mathrm{Hg})$.

Next one may try to include other oxidation states. To do so and retain charge-neutral systems there are three basic options: (i) change the $A B X_{3}$ composition, e.g., by employing a divalent $X$-site anion. This, however, for example in the form of HP oxides or sulfides, seems to be a route that has not been explored yet.(ii) By introducing vacancies, elements with $\mathrm{OS}>+2$ can be incorporated into an $\mathrm{HP}(\mathrm{A})$ framework. (iii) Last, by employing mixed OS on any of the three ionic sites, a variety of different OS can be employed.

Since the first option seems to be unexplored, we will start by a discussion of the second route, high-charge cations in combination with vacancies. $\mathrm{A}+3$ metal can be incorporated on the $B$-site by leaving $1 / 3$ of the $B$-sites empty, i.e., in $A_{3} B_{2} X_{9}$. Such a concept is quite old and has been explored for $\operatorname{HP}(\mathrm{A})$ related $\mathrm{Cs}$ systems like $\mathrm{Cs}_{3} \mathrm{Bi}_{2} \mathrm{I}_{9}$ and $\mathrm{Cs}_{3} \mathrm{Sb}_{2} \mathrm{I}_{9}[149,150]$ and other alkali-metals ( $A=\mathrm{K}, \mathrm{Rb}, \mathrm{Cs}) \cdot[151]$ In the mean-time, it has also been applied to $\mathrm{HP}(\mathrm{A}) \mathrm{s}$, e.g., in $(\mathrm{GA})_{3} B_{2} \mathrm{I}_{9}(B=\mathrm{Bi}, \mathrm{Sb}) .[152]$ To date, such structures were not found as perovskites but preferring hexagonal or layered structures. The absence of the perovskite crystal structure for these cases might be related to the fact that removing $1 / 3$ of an integral part of the structure like the $B X_{6}$ octahedra might be too drastic a modification, especially considering that the ionic radius of $\mathrm{Bi}^{3+}$ leads to very promising tolerance factors close to 1 in hypothetical $\mathrm{CsBiX}_{3}$ compounds. However, despite this structural change, this route shows promise in terms of PV properties and material stability and will certainly be explored further in the future.[82]

Although it appears hard to imagine group XIII elements in $\mathrm{OS}=+2$, computational screening yields hypothetical perovskites that are, surprisingly, nonmetallic for Ga and In.[116] Since this electronic state appears unusual, such compounds might be unreasonable due to high formation energies, which requires further study.

Next, we summarize the class of charge disproportioned HP systems, where one site is occupied by (different or the same) ions in two different OS. In this way, other OS can be incorporated in $A B X_{3}$ compounds, without leaving sites fractionally occupied. This concept can, in principle, be employed on all sites of the perovskite structure, and even complex designs with disproportionation on several sites is possible.

We start with the most commonly employed approach, which is charge disproportion on the $B$-site in $A_{2} B B^{\prime} X_{6}$ stoichiometries. $B$ and $B^{\prime}$ can be the same element. Such structures are well known for $A_{2} B B \mathrm{O}_{6}$ oxides and have been reviewed, e.g., by Vasala.[153] The same concept, of course can also be applied for halides (e.g., $\mathrm{Cs}_{2} \mathrm{Au}^{+} \mathrm{Au}^{3+} \mathrm{I}_{6}$ ). [20] In order to replace a $+2 B$-site ion, elements with stable $\mathrm{OS}=+1$ and +3 are most suitable, such as group XI $(\mathrm{Cu}, \mathrm{Ag}$, and $\mathrm{Au})$, group X (mainly Pd), and group XIII (mainly $\mathrm{Tl}$ ) elements. Structures of this type have been reported as $A_{2} \mathrm{Au}^{+} \mathrm{Au}^{3+} X_{6}(A=\mathrm{K}, \mathrm{Rb}$, or Cs; $X=\mathrm{Cl}, \mathrm{Br}$, or I),[154] and $\mathrm{Cs}_{2} \mathrm{Tl}^{+} \mathrm{Tl}^{3+} X_{6}(X=\mathrm{F}$ or $\mathrm{Cl}) .[155]$ Of course, this concept is not just limited to a single elemental species, but can also be used to mix elements in order to employ other OS (although in such a case, the term 
disproportionation is technically incorrect). For example this was demonstrated for $\mathrm{Cs}_{2} \mathrm{Ag}^{+} \mathrm{Au}^{3+} \mathrm{Cl}_{6}[156]$ or $\mathrm{Cs}_{2} \mathrm{Ag}^{+} \mathrm{Bi}^{3+} \mathrm{Br}_{6}$. [157] Computational screening of such $\mathrm{Cs}_{2} B B^{\prime} X_{6}$ structure $\left(B^{\prime}=\mathrm{Sb}\right.$ and $\mathrm{Bi} ; B=\mathrm{Cu}, \mathrm{Ag}$ and $\left.\mathrm{Au}\right)$ has been carried out by Volonakis and co-workers[158] and finally including organic $A$ site molecules by Kim,[139] after this concept was first employed for HPs for $(\mathrm{MA})_{2} \mathrm{Tl}^{+} \mathrm{Bi}^{3+} \mathrm{I}_{6} \cdot[159]$

In addition to directly balancing charges by mixing ions on the $B$-site, an alternative approach is charge neutralization via a mixture of $X$-site anions. For current purposes (keeping $A^{+}$cations and trying to include $\mathrm{OS}=+1$ and +3 $B$-sites), the most useful replacement is incorporating $1 / 3 Y^{2-}$ anions to form $A^{+} B^{3+} Y X_{2}$ compounds. Naturally, chalcogens appear best suited for pairing with $X$-site halides. Again, this concept was first employed for inorganic HP analogs. Hong and co-workers investigated a series of $A B Y X_{2}$ compounds with $A=\mathrm{Ba}$ or $\mathrm{Cs}, B=\mathrm{Sb}$ or $\mathrm{Bi}, Y=\mathrm{O}, \mathrm{S}, \mathrm{Se}$, or Te, and $X=\mathrm{F}, \mathrm{Cl}, \mathrm{Br}$, or I.[160] This initial investigation, however, showed that such compounds are prone to decomposition due to thermodynamic instability and, thus, this modification has not yet yielded much promise.

In any case, design concepts such as the introduction of empty sites or charge disproportion are routes to include elements in $\mathrm{OS}=+1$ or +3 into established $A B X_{3} \mathrm{HP}(\mathrm{A})$ s. In addition to the investigated group XIII and XIV elements, third-row transition-metals or rare-earth metals are further options to add into the compositional mix.

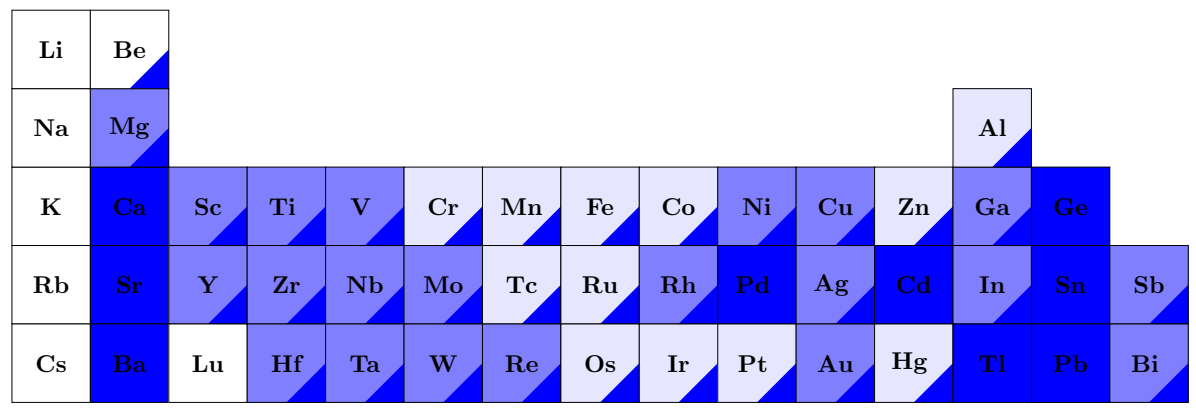

Figure 3: Possible metals that can be employed in $A B X_{3} \mathrm{HP}(\mathrm{A}) \mathrm{s}$ (filled) or $A_{2} B B^{\prime} X_{6}$ (colored corner), with $A=\mathrm{Cs}$, MA, or FAd. Data obtained from Refs. $[116,138]$ and other examples from the text. Note that these computational screenings often did not take the thermodynamic stability or alternate phases into account. Hence, we note candidates as possible, based on estimated $t$ or other results (light colors). In cases where the coarse computational screening yielded perovskites only for inorganic compounds $(A=\mathrm{Cs})$, this is indicated by an even lighter shading.

In Fig. 3, we collected the metals that have been screened in $A B X_{3}$ and $A_{2} B B^{\prime} X_{6}$ compounds, mainly relying on Refs. $[116,138]$ From this we can draw a couple of conclusions: (i) if solely limited to $A B X_{3}$ compounds, the pool of possible metals is rather limited. Other than three outliers $(\mathrm{Pd}, \mathrm{Cd}$, and $\mathrm{Tl}$ ), one may mainly choose from alkaline-earth metals or group XIV. A couple of other metals have been proposed; however, they are often at the boundary in terms of ionic size, allowing them to make the cut in case of $\mathrm{Cs}^{+}$on the 
$A$-site, but already too small for the slightly larger organic cations. Others, are hardly known in the proposed OS of +2 and further stability analysis and investigation of the electronic state is necessary in order to trust these results. On the other hand, if more sophisticated design principles are employed, e.g., $B$-site disproportion, the pool of potential prospects explodes and almost spans the entire periodic table. Besides the ones considered so far, such structural modification would even allow incorporation of rare-earth metals. Besides the fact that other OS become feasible, the reason for this is that an $A_{2} B B^{\prime} X_{6}$ stoichiometry also allows to employ much smaller $B$ ions, by pairing them with larger $B^{\prime}$ ions.

To this point, we only considered organic $A$-site molecules in $\mathrm{OS}=+1$. In the mean-time, other compounds have also been investigated, starting with an investigation by Panton of a class of $B$-site alkali metal chloride HP(A)s with divalent organic cations (see Fig. 4).[161] These structures are particularly interesting, since they not only require different OS on the $B$-site, but the employed dications are also significantly larger compared to traditional $A$-site cations, allowing much larger inorganic $B$-site cations. Both reasons make completely different areas of the periodic table accessible in these $\mathrm{HP}(\mathrm{A}) \mathrm{s}$, e.g., alkali metals. All the investigated $A B \mathrm{Cl}_{3}$ compounds $(B=$ alkali metal) with piperazine-1,4-diium $\left(\mathrm{PA}_{2}\right)$ cations on the $A$-site crystallize as perovskites, stabilized via the inclusion of water. In case of the sterically more demanding 1,4-diazabicyclo[2.2.2] octane-1,4-diium (DABCO- $\mathrm{A}_{2}$ ), the smallest $B$-site cation $\left(\mathrm{K}^{+}\right)$forms a hexagonal perovskite, whereas the larger alkali metals $\left(\mathrm{Rb}^{+}\right.$and $\left.\mathrm{Cs}^{+}\right)$form perovskites. This is in line with the known behavior for $t>1$ and small $B$-site ions (see above). This research triggered similar investigations by $\operatorname{Pan}[162]$ and Zhang[163], investigating 3-ammoniopyrrolidin-1ium (APA) and 1-methyl-1,4-diazabicyclo[2.2.2] octane-1,4-diium (M-DABCO$\mathrm{A}_{2}$ ) compounds (APA) $\mathrm{RbBr}_{3}$ and (M-DABCO- $\left.\mathrm{A}_{2}\right) \mathrm{RbI}_{3}$, respectively, all forming perovskites. With their study, Zhang et al. demonstrate how the increased space can be used to fine-tune molecular properties to alter the HP crystal properties. When reducing the symmetry by removing a mirror plane in the organic $A$-site, the non-ferroelectric DABCO- $\mathrm{A}_{2}$ compound is transformed to a ferroelectric compound, when employing the methylated cation (M-DABCO$\mathrm{A}_{2}$ ) with its molecular dipole moment.

Having discussed compositional and structural modifications for $\mathrm{HP}(\mathrm{A}) \mathrm{s}$, we can now consider the gain in terms of increasing the pocket of the $B X_{3}$ backbone to incorporate a larger variety of (sterically more demanding) organic cations on the $A$-site. In terms of $X$-site anions, $\mathrm{I}^{-}$is already the largest inorganic anion. $X$ site charge variation does not increase the design possibilities, since the largest chalcogenide $\left(\mathrm{Te}^{2-}\right)$ is only insignificantly larger, at least as long as we do not take more exotic, metallic anions into account.[104] However, by considering disproportionation on the $B$-site, we can make use of large +1 cations (e.g. $\left.\mathrm{Cs}^{+}\right)$and pair them with the largest +3 cations $\left(\mathrm{Bi}^{3+}\right)$. In such an iodide, the $A$-site pocket as determined by the $B-\mathrm{I}-B$ bond (assuming a perfect structure) compared to $\mathrm{Pb}-\mathrm{I}-\mathrm{Pb}$ is increased by $0.53 \AA$, i.e., $A$-site cations that are larger than MA by this amount should be able to form $\operatorname{HP}(\mathrm{A}) \mathrm{s}$. Furthermore, when considering organic dications, the maximal $\mathrm{CsI}_{3}$ backbone has a $B-\mathrm{I}-B$ length that is increased by $1.38 \AA$, allowing a significant increase of $A$-site cations, as demonstrated by the $\mathrm{DABCO}$ and $\mathrm{PA}_{2}$ examples above. All these examples and new possibilities promise to aid in the discovery and cultivation of lead-free HP 


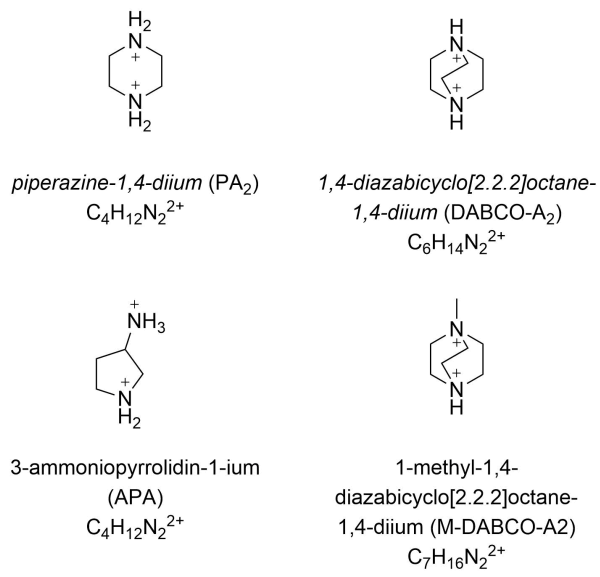

Figure 4: List of organic divalent cations considered in $\operatorname{HP}(A)$ structures. Names printed in italics represent molecules that enable a symmetric bonding with two identical groups.

PVs but could also provide many other interesting properties.

\subsection{Organic X-site: $\mathrm{HP}(\mathrm{X})$}

As mentioned above, conceptually there is nothing special about (MA) $\mathrm{PbI}_{3}$ or any other $\mathrm{HP}(\mathrm{A})$, and it is also possible to form HPs with organic anions on the $X$-site $(\mathrm{HP}(\mathrm{X}))$. Note, however, that the shift from spherical (inorganic) ions to organic molecules is accompanied by a new sense of (bonding) direction. Hence, $B \cdots X \cdots B$ bridging capabilities have to be taken into account during the design. As another complication compared to all spherical ions, one needs to keep in mind that controlling $\mathrm{HP}(\mathrm{X})$ structures to an extent that would enable useful coordination in $A X_{12}$ cuboctahedra by direct anchoring between $A$ - and $X$-sites is challenging, requiring quite large structures. Instead, supramolecular interactions like Coulomb interactions, hydrogen bonds, or van der Waals interactions play a more important role in the resulting more complex structures.[164] Thus, from a design standpoint, such structures are much more flexible, leading to a vast increase of complexity but also potentially offering favorable properties once all materials design tuning knobs are understood and controllable. In any case, the multiatomic $X$-site ions need to have two anchor groups to bind $B$-sites. Multiple $X$-site ions can be used, and they can be asymmetric. Employing $X$-site anions with two different anchoring groups is a natural way to induce $B$-site off-center displacements, which can lead to polar structures, as has been demonstrated for inverse-hybrid perovskites (see below). Furthermore, the elongated $X$-site does not have to be linear, but the range of allowed angles is certainly limited in order to retain the perovskite structure. If more than two anchoring groups are introduced, especially, in low symmetry ions, fabricating well-ordered bulk cubic perovskites without disorder would become extremely challenging.

A prime example of an organic ligand with the above properties is cyanide $\left(\mathrm{CN}^{-}\right)$. It is linear and well known to bind multiple metals, such as Fe in prus- 
sian blue. In the group of Miller, a series of alkali metal $A_{2} \mathrm{Mn}^{2+} \mathrm{Mn}^{2+}(\mathrm{CN})_{6}$ compounds with $A=\mathrm{Na},[165] \mathrm{K},[166] \mathrm{Rb},[166]$ and $\mathrm{Cs}[167]$ were investigated starting in 2010. Much earlier than this, Thiele and Messer investigated alkali metal $\left(A=\mathrm{Rb}\right.$ and $\mathrm{Cs}$ ) thiocyanates $A \mathrm{Cd}(\mathrm{SCN})_{3} .[168]$ While they report a layered structure for the $\mathrm{Rb}$ compound, $\mathrm{CsCd}(\mathrm{SCN})_{3}$ forms a perovskite structure. This is in line with a smaller tolerance factor in the $\mathrm{Rb}$ case for such a large $X$-site anion.

The first report of a formate $\mathrm{HP}(\mathrm{X})$ is also from the 1980s[169]. This was picked up later, leading to a class of potassium perovskites $\mathrm{KB}(\mathrm{HCOO})_{3}, B=$ $\mathrm{Co},[170] \mathrm{Mn},[171]$ and $\mathrm{Cd} .[169] \mathrm{KCo}(\mathrm{HCOO})_{3}$ reportedly prefers a different phase, but can be observed as perovskite after an irreversible phase transition.[170] There are also reports on $\mathrm{NaMn}(\mathrm{HCOO})_{3},[171,172]$ but the smaller alkali metal does not allow the perovskite structure. Thus, the formate anion appears to be too large to form $\mathrm{HP}(\mathrm{X})$ materials, with only few examples. Nevertheless, the alternative hexagonal structures yield intriguing chiral cases, due the observed uniqueness of octahedral coordination.[170, 172] Such structures have also been observed for $\left(\mathrm{NH}_{4}\right) \mathrm{M}(\mathrm{HCOO})_{3}$, with $\mathrm{M}=\mathrm{Mn}$, Co, Ni.[173]

The recurring scheme of these scarce examples for $\mathrm{HP}(\mathrm{X})$ structures is: (i) most organic anions are too large for an otherwise (monoatomic) inorganic perovskite lattice, and there are only few reported examples, (ii) all the $X$-site anions we discussed so far are monovalent, leading to alkali metals as natural $A$-site partners, and (iii) a variety of $d$-block configurations can be accommodated on the $B$-site. In terms of the spectrochemical series, it is interesting that a large range is present, from strong-field $\mathrm{CN}^{-}$to weak-field $\mathrm{SCN}^{-}$. It is also an interesting concept keeping in mind the inhomogeneity of the discussed ligands (besides formate), and the resulting different anchoring strengths. This could be used as an additional design knob to stabilize disproportionate structures, although, to our knowledge, such structures have only been explored in biorganic hybrid perovskites (see below).

\section{Perovskites with more than one organic ion}

HPs that contain two organic ions have, to the best of our knowledge, not yet been distinguishably labeled. This may be attributed to the fact that research on such structures is yet scarce and a link towards the term HPs is rather new and came not before the recent prominence of this materials class with respect to PV applications. Furthermore, they were often formed in systems with charge disproportioned $B$-sites in so-called double perovskites, which already reserves the use of "double" (preempting terminology like, e.g., double-hybrid perovskite). To distinguish this class from HPs with one organic group, one could introduce the term "biorganic". However, with the notation we propose, we can unambiguously refer to them by the sites referring to organic ions given in brackets HP(AX). The first successful example of a biorganic HP was reported a few years after the first $\mathrm{HP}(\mathrm{X})$ structures,[174] employing tetraethylammonium on the $A$-site and an azide anion on the $X$-site, forming an $\operatorname{HP}(\mathrm{AX})$ structure. Due to size considerations, $\mathrm{HP}(\mathrm{BX})$ is unlikely and the only other possible variant appears to be $\mathrm{HP}(\mathrm{AB})$ structures. 


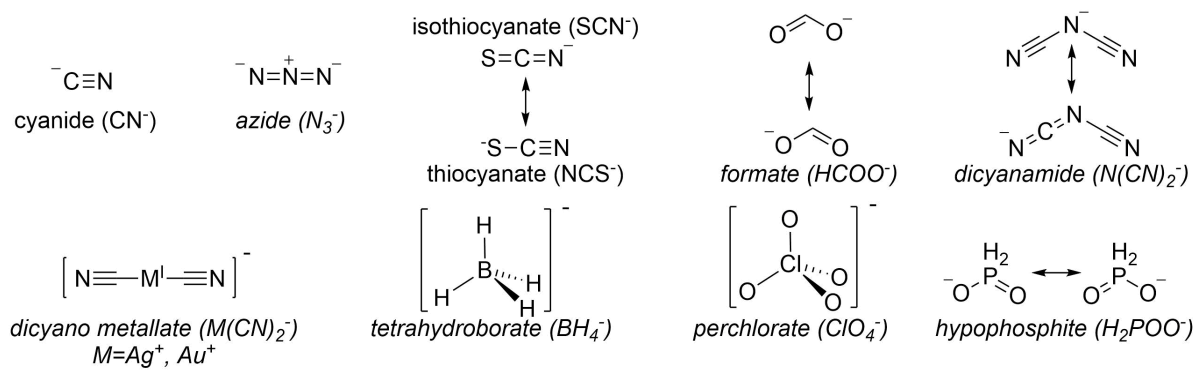

Figure 5: List of organic monovalent anions considered in $\operatorname{HP}(\mathrm{X})$ and $\operatorname{HP}(\mathrm{X})$ structures. Names printed in italics represent molecules that enable a symmetric bonding with multiple (two to four) identical groups. Important resonance structures indicating bridging patterns are indicated. To date, no divalent anions have been employed in HPs.

\subsection{Organic A- and X-sites: $\mathrm{HP}(\mathrm{AX})$}

Reviews of this class can be found in Refs.[81, 164, 175] $\mathrm{HP}(\mathrm{AX})$ structures employ many of the ligands we discussed for $\mathrm{HP}(\mathrm{A})$ and $\mathrm{HP}(\mathrm{X})$ compounds. In addition, biorganic HPs also allow larger ligands due to the simultaneous increase of $A$ - and $X$-site ions. Since the perovskite backbone is dominated by the $B X_{3}$ subgroup, $\operatorname{HP}(\mathrm{AX})$ structures are mainly classified by the $X$-site anion. To this point, only monovalent organic anions have been employed, including cyanide $\left(\mathrm{CN}^{-}\right)$, azide $\left(\mathrm{N}_{3}^{-}\right)$, thiocyanate $\left(\mathrm{SCN}^{-}\right)$, dicyanamide $\left(\mathrm{N}(\mathrm{CN})_{2}^{-}\right)$, formate $\left(\mathrm{HCOO}^{-}\right)$, dicyano metallates $\left(\mathrm{M}(\mathrm{CN})_{2}^{-}\right)$, borohydride $\left(\mathrm{BH}_{4}^{-}\right)$, and perchlorate $\left(\mathrm{ClO}_{4}^{-}\right)$, see Fig. 5. The most recent addition to this list is hypophsphite $\left(\mathrm{H}_{2} \mathrm{POO}^{-}\right)[176]$. Although limited, this is already an interesting list including linear and bent ligands as well as ligands with homogeneous or heterogeneous anchoring groups.

This rather recent addition of $\mathrm{HP}(\mathrm{AX})$ to the $\mathrm{HP}$ universe already yielded structures with interesting physical properties, such as anomalous barocaloric effects as well as electric and/or magnetic order (leading to multiferroicity), see Ref. [175] and references therein. The larger $B X_{3}$ cage also allows to functionalize the space within the perovskite lattice, e.g., for hydrogen storage.[177]

In the future, the range of ions is likely to be expanded. There are still monovalent molecular structures to be included into $\mathrm{HP}(\mathrm{X})$ or $\mathrm{HP}(\mathrm{AX})$ networks, especially oxygen containing ligands, e.g., hydrogen sulfate, chlorate, or acetate. Moreover, divalent anions can be employed along similar lines, e.g., sulfate or hydrogen phosphate, opening a whole new realm of oxidation states for the partnering cations, analogous to what we discussed for the introduction of chalcogenides in $\mathrm{HP}(\mathrm{A}) \mathrm{s}$ above. With increasing size of the $B X_{3}$ pocket and complexity of the ligands, engineering of the supramolecular interactions will become vital and very interesting. At some point, this might lead to covalent bond formation between the ionic compounds, e.g., between $A$ - and $X$-sites, enabling potentially very well-organized 3D MOFs. Such more rigid structures would certainly have different properties compared to the dynamical nature of the $A$-site cation in $\mathrm{HP}(\mathrm{A}) \mathrm{s}$. For example, this could be a promising route toward structures that are more stable towards moisture and air. On the other 
hand, the chemistry of such organic anions, especially in combination with other organic groups holds additional aspects that need to be considered with respect of the stability of potential compounds. Due to their oxidizing nature, e.g., chlorates could react with the acidic ammoniums towards chlorine, water, and the corresponding amine, leading to a dissolution of the structure from within. No such problems were reported in the initial works[178, 179] on perchlorates, but detailed stability analysis is yet missing.

\subsection{Organic A- and B-sites: $\mathrm{HP}(\mathrm{AB})$}

With much less attention, HPs with molecular $A$ - and $B$-sites have only been reported once by Bremner et al. in 2002. They reported a compound of the formula $\left(\mathrm{PA}_{2}\right)\left(\mathrm{NH}_{4}\right) \mathrm{Cl}_{3} \cdot \mathrm{H}_{2} \mathrm{O}$, requiring the incorporation of water in the crystal for stabilization (see Fig. 4).[180] Besides being the first and to date only $\mathrm{HP}(\mathrm{AB})$, this compound introduces another interesting concept: since size is the overall dominating factor with respect to distributing ions on the $A$ - and $B$ sites, in such a structure with two molecular organic cations, the higher charged cation may be the larger one. Consequently, the larger dication $\mathrm{PA}_{2}$ occupies the $A$-site, with the smaller ammonium $\left(\mathrm{NH}_{4}{ }^{+}\right)$occupying the $B$-site. As noted above, supramolecular interactions (here hydrogen bonds) dominate the binding in such a compound. This does not necessarily mean that such structures are unstable or less stable than other HPs. For example, Bremner et al. reported a weight loss interpreted as release of water from the crystal between 62 and $145^{\circ} \mathrm{C}$, however, the dehydrated compound is stable until $600{ }^{\circ} \mathrm{C}$. Nevertheless, the bonding via the anchoring groups and the steric demand is harder to balance. For example, an analogous compound (DABCO- $\left.\mathrm{A}_{2}\right)\left(\mathrm{NH}_{4}\right) \mathrm{Cl}_{3}$ utilizing the dabconium dication (instead of $\mathrm{PA}_{2}$ ) prefers a face-sharing phase instead of the perovskite structure.

\subsection{Organic Perovskites: OP}

Since successful examples of organic cations and anions occupying the perovskite structure exists, in principle, the incorporation of three organic cations should be possible as well. Such an organic perovskite (OP) has only been reported once by Liu et al. [181] These authors reported on (DABCO-A 2$)\left(\mathrm{NH}_{4}\right)\left[\mathrm{BF}_{4}\right]_{3}$, i.e., using the same system as Bremner et al. but replacing the chloride anions by the larger tetrafluorborate $\left(\mathrm{BF}_{4}^{-}\right)$.

These two model cases have in common that the higher charge is located on the larger molecule on the $A$-site and that hydrogen bonding stabilizes the crystal structure. Of course, the classification of $\mathrm{BF}_{4}^{-}$as organic or inorganic might be viewed as a matter of semantics and this might as well be classified as $\mathrm{HP}(\mathrm{AB})$. Nevertheless, OPs are obviously possible.

Unfortunately, due to the limited research on $\mathrm{HP}(\mathrm{AB}) \mathrm{s}$ and $\mathrm{OPs}$, not much is known about their properties. One direct motivation to study these materials is the possibility of expanding the volume of the unit cell and, therefore, being able to employ different, larger molecules.

The complexity of these structures could also hold interesting promise. For example, complex $A$-site ions enabled in $\operatorname{HP}(\mathrm{AX})$ or $\mathrm{OP}$ structures could serve as interesting active sites, enabling storage of small molecules (e.g., hydrogen) or as catalytic centers in confined space. The vast possibilities of organic molecules 
and inorganic clusters that could potentially be combined in the highly ordered perovskite (or related) phases, makes them a potentially promising subclass of MOFs.

\section{Inverse hybrid perovskites}

\subsection{Organic X-site: $\operatorname{IHP}(X)$}

Although most perovskites employ cations on $A$ and $B$ and an anionic species on $X$ and this can be regarded as standard, this Coulombic order can, as mentioned in the introduction, be reversed to so-called inverse or anti perovskites (IP). Despite the overwhelming varsity of traditional perovskites, a significant number of IPs are known with many fascinating properties.

A first analog to an IP incorporating an organic group was given by Batail and co-workers, [182] who reported on a family of compounds containing a tetrathiafulvalene radical cation $\left(\mathrm{C}_{6} \mathrm{H}_{4} \mathrm{~S}_{4}^{+*}\right.$, TTF see Fig. 2) and $\mathrm{Mo}_{3} X_{14}^{2-}$ clusters in (TTF) ${ }_{3} Y\left(\mathrm{Mo}_{3} X_{14}\right)$ compounds with $X=Y=\mathrm{Cl}$ and $X=\mathrm{Br}, Y=\mathrm{Cl}, \mathrm{Br}$, I. The organic TTF radical connects two $B$-sites in a side-on coordination, leading to an $\mathrm{S}^{\delta+} \ldots Y^{-} \ldots \mathrm{S}^{\delta+}$ bonding motif. The compounds are paramagnetic but show anti-ferromagnetic ordering at low temperature.[182] These materials were later also studied theoretically[183] and analyzed further by Hiramatus et al.[184] The latter study also investigated the replacement of Sulfide against Selenide, employing a tetraselenafulvalene radical cation $\left(\mathrm{C}_{6} \mathrm{H}_{4} \mathrm{Se}_{4}^{+\cdot}\right.$, TSF)

Besides these early examples with quite large cage size, we recently reintroduced this IHP concept in, $[109,185,186]$ motivated by the quest to broaden the scope of inorganic-organic hybrid materials in the perovskite structure. We hypothesize that IHPs could tackle the main drawbacks of the workhorse of HP PVs: dissolution in aqueous media and toxicity concerns. In rather comprehensive studies on (MA) ${ }_{3} B A$ compounds, we explored the possibility to include main group elements and transition metals as mono and divalent anions. Guided by known oxidation states of elements and novel effective ionic radii for these anionic species[104], we found that a tolerance factor of at least $t=0.76$ is required, or otherwise the related $\mathrm{CaIrO}_{3}$ phase is favored. For both phases, hydrogen bonding of the $\mathrm{MA} \mathrm{NH}_{3}^{+}$and $\mathrm{CH}_{3}$ end groups dominate the structure. Due to the inhomogeneity of these anchoring groups, the investigated structures displayed inherent off-center displacements and nonzero polarization.

As a major difference to traditional perovskites, we find that noncubic $(\mathrm{MA})_{3} B A$ IHP structures $(t \neq 1)$ are stabilized by a tilting of the MA molecules in the $B \cdots X \cdots B$ bridge, which can either be tilted head-on or side-on, as observed in the TTF bridges. Thus, no octahedral rotations are observed even for structures with $t$ differing considerably from unity.

When employing electronegative, light elements on the $B$-site, protonation is observed. For some cases (oxygen or sulfur) this leads to the formation of intriguing hydrogen-bonding networks with potential for dynamic proton exchange. For others, this leads to a destabilization of the perovskite structure. On one hand, the size of ions dominates not only the compatibility of a certain composition, but also dominates the site selectivity on $A$ - and $B$-sites over the oxidation state of employed anions. In that regard, tuning the halide proved to be a valuable tool in order to stabilize the perovskite structure with specific 
divalent anions.

A special focus in our studies was the electronic properties of these compounds. While MA chalcogenide halide IHPs are exclusively wide band gap semiconductors, employing other main group and transition metals leads to the formation of metallic, semimetallic, as well as semiconducting IHP(X)s. In particular, two features are intriguing. First, in structures employing group XII through XV elements on the $B$-site, the valence $p$ shell of the divalent anions are located at the Fermi level. Since these bands are split by spin-orbit coupling in the case of heavy elements (periods five and six), one observes double-degenerate linear crossing points throughout the Brillouin zone.

Second, we found several systems with band gaps perfectly suited for PV applications. Besides some systems employing toxic heavy-metals, we identified $(\mathrm{MA})_{3} \mathrm{FNi}$ and $(\mathrm{MA})_{3} \mathrm{FPd}$. These could be particularly interesting as lead-free alternatives to the successful $A \mathrm{PbI}_{3}$ compounds.

Despite these investigations, IHPs are the newest and least explored addition the perovskite universe. Thus, experimental synthesis of the proposed prospects is still ongoing, however, the first study confirming our prediction of ferroelectric IHPs was reported on the compound $\mathrm{MA}_{3}\left(\mathrm{MnBr}_{3}\right)\left(\mathrm{MnBr}_{4}\right)$.[187] Furthermore, the investigation of other organic $A$-site cations or even the investigation of inverse-biorganic perovskites is still uncharted territory.

\begin{tabular}{ccc}
\hline \hline$X$ & $B$ & $A$ \\
\hline MA & $\mathrm{F}$ & $\mathrm{Ga}, \mathrm{Tl}, \mathrm{Ge}, \mathrm{Sn}, \mathrm{Pb}, \mathrm{S}, \mathrm{Se}, \mathrm{Te}, \mathrm{Zn}, \mathrm{Cd}, \mathrm{Hg}, \mathrm{V}, \mathrm{Mn}, \mathrm{Ni}, \mathrm{Pd}, \mathrm{Pt}$ \\
MA & $\mathrm{O}$ & $\mathrm{I}, \mathrm{Au}$ \\
MA & $\mathrm{S}$ & $\mathrm{I}$ \\
MA & $\mathrm{Se}$ & $\mathrm{I}, \mathrm{Bi}$ \\
TTF & $\mathrm{Cl}$ & $\mathrm{Mo}_{3} \mathrm{Cl}_{14}$ \\
TTF & $\mathrm{Br}$ & $\mathrm{Mo}_{3} X_{14}, X=\mathrm{Cl}, \mathrm{Br}, \mathrm{I}$ \\
TSF & $\mathrm{Cl}$ & $\mathrm{Mo}_{3} \mathrm{Cl}_{14}$ \\
TSF & $\mathrm{Br}$ & $\mathrm{Mo}_{3} \mathrm{Br}_{14}$ \\
\hline \hline
\end{tabular}

Table 2: List of investigated IHP(A) structures that favor the perovskite structure over related phases, like hexagonal perovskites or face-sharing structures.

\section{Conclusion}

The excitement surrounding HP PVs based on the $A \mathrm{~Pb} X_{3}$ family has not only led to extensive research in the limited compositional space of $\mathrm{HP}(\mathrm{A})$ structures, but also helped to trigger research on many other organic, molecular motifs in the perovskite structure. While $\mathrm{HP}(\mathrm{A})$ structures are somewhat constrained in the sense that the perovskite backbone is directly related to that of the inorganic halide sublattice, the supramolecular bonding aspect that is important for understanding structural details in $\mathrm{HP}(\mathrm{A}) \mathrm{s}$, becomes dominant in all other HP structures. While this gives researchers more things to consider in order to lay out a successful design, it also brings tremendous possibilities. The combination of larger ions on more than one site will enable the use of a significantly expanded set of ions that could form a 3D crystal. The supramolecular design 
necessary for this will benefit from the concepts and knowledge gained from MOFs, with HPs being more and more established as an important subclass.

Increasing the size of the perovskite unit cell dimensions by incorporating organic groups will also open the possibility to incorporate larger inorganic groups or clusters in the well-ordered perovskite structure, and thus conversely enhance the structural control of MOFs. Finding next generation HPs for PVs is, therefore, also only a small fraction of envisioned properties of this new structural variety. Besides new twists and tuning possibilities for the many interesting features found in traditional perovskites, the increased pore size could enable completely new fields for applications with respect to storage, ion transport, or confined space chemical reactions. Thus, in our view there is a lot to come from mixing and matching inorganic and organic ions in the (inverse) perovskite lattice. The exploration of complex, supramolecular perovskites has just begun.

\section{Acknowledgement}

J. G. thanks the German Research Foundation for support from Research Fellowships GE 2827/1-1 and GE 2827/2-1. A. M. R acknowledges support of the National Science Foundation, grant DMR/1719353.

\section{References}

[1] J. Hwang, R. R. Rao, L. Giordano, Y. Katayama, Y. Yu, Y. Shao-Horn, Science 2017, 358, 751-756.

[2] K. Hirose, R. Sinmyo, J. Hernlund, Science 2017, 358, 734-738.

[3] S. D. Ha, S. Ramanathan, J. Appl. Phys. 2011, 110, 071101.

[4] J. Xiao, J. A. Paixiao, M. M. R. Costa, D. Sun, Recent Patents Mater. Sci. 2012, 5, 159-165.

[5] A. Bhalla, R. Guo, R. Roy, Mater. Res. Innov. 2000, 4, 3-26.

[6] F. Dogan, H. Lin, M. Guilloux-Viry, O. Peña, Sci. Technol. Adv. Mater. 2015, 16, 020301.

[7] Q. Sun, W. J. Yin, J. Am. Chem. Soc. 2017, 139, 14905-14908.

[8] M. A. Peña, J. L. G. Fierro, Chem. Rev. 2001, 101, 1981-2017.

[9] L. W. Martin, A. M. Rappe, Nat. Rev. Mater. 2016, $2,16087$.

[10] M. E. Lines, A. M. Glass, Principles and Applications of Ferroelectrics and Related Materials, Clarendon Press, Oxford, 1977.

[11] A. Chroneos, R. V. Vovk, I. L. Goulatis, L. I. Goulatis, J. Alloys Compd. 2010, 494, 190-195.

[12] Z. Fan, K. Sun, J. Wang, J. Mater. Chem. A 2015, 3, 18809-18828.

[13] E. Grabowska, Appl. Catal. B Environ. 2016, 186, 97-126.

[14] S. Picozzi, K. Yamauchi, I. A. Sergienko, C. Sen, B. Sanyal, E. Dagotto, J. Phys. Condens. Matter 2008, 20, 434208.

[15] R. Ramesh, N. A. Spaldin, Nat. Mater. 2007, 6, 21-29. 
[16] N. Setter, D. Damjanovic, L. Eng, G. Fox, S. Gevorgian, S. Hong, A. Kingon, H. Kohlstedt, N. Y. Park, G. B. Stephenson, I. Stolitchnov, A. K. Taganstev, D. V. Taylor, T. Yamada, S. Streiffer, J. Appl. Phys. 2006, 100, 051606.

[17] H. Tanaka, M. Misono, Curr. Opin. Solid State Mater. Sci. 2001, 5, $381-387$.

[18] J. Zhu, H. Li, L. Zhong, P. Xiao, X. Xu, X. Yang, Z. Zhao, J. Li, ACS Catal. 2014, 4, 2917-2940.

[19] T. Wolfram, S. Ellialtioglu, Electronic and optical Properties of d-Band Perovskites, Cambridge University Press, Cambridge, 2006.

[20] L. Debbichi, S. Lee, H. Cho, A. M. Rappe, K. H. Hong, M. S. Jang, H. Kim, Adv. Mater. 2018, 30, 1707001.

[21] J. B. Neaton, K. M. Rabe, Appl. Phys. Lett. 2003, 82, 1586-1588.

[22] M. Dawber, C. Lichtensteiger, M. Cantoni, M. Veithen, P. Ghosez, K. Johnston, K. M. Rabe, J.-M. Triscone, Phys. Rev. Lett. 2005, 95, 177601.

[23] M. Sepliarsky, S. R. Phillpot, D. Wolf, M. G. Stachiotti, R. L. Migoni, Phys. Rev. B 2001, 64, 060101(R).

[24] R. Nechache, C. Harnagea, S. Licoccia, E. Traversa, A. Ruediger, A Pignolet, F. Rosei, Appl. Phys. Lett. 2011, 98, 202902.

[25] N. Sai, B. Meyer, D. Vanderbilt, Phys. Rev. Lett. 2000, 84, 5636-5639.

[26] S. M. Nakhmanson, K. M. Rabe, D. Vanderbilt, Appl. Phys. Lett. 2005, 87, 102906.

[27] H. Nyung Lee, H. M. Christen, M. F. Chisholm, C. M. Rouleau, D. H. Lowndes, Nature 2003, 433, 395-399.

[28] L. Jiang, I. Grinberg, F. Wang, S. M. Young, P. K. Davies, A. M. Rappe, Phys. Rev. B 2014, 90, 075153.

[29] J. S. Lim, D. Saldana-Greco, A. M. Rappe, Phys. Rev. B 2018, 97, 045115 .

[30] V. M. Goldschmidt, Naturwissenschaften 1926, 14, 477-485.

[31] V. M. Goldschmidt, T. Barth, G. Lunde, W. H. Zachariasen, Geochemische Verteilungsgesetze der Elemente, Skr. norske Vidensk. Akad. 1, Mat.Nat. Kl. No. 2, 1926.

[32] A. M. Glazer, Acta Crystallogr. Sect. B Struct. Crystallogr. Cryst. Chem. 1972, 28, 3384-3392.

[33] A. M. Glazer, Acta Crystallogr. Sect. A 1975, 31, 756-762.

[34] H. T. Stokes, E. H. Kisi, D. M. Hatch, C. J. Howard, Acta Crystallogr. Sect. B Struct. Crystallogr. Cryst. Chem. 2002, B58, 934-938.

[35] H. Brasseur, L. Pauling, J. Am. Chem. Soc. 1938, 60, 2886-2890.

[36] F. Rodi, D. Babel, Z. anorg. allg. Chemie. 1965, 336, 17-23.

[37] J. A. Brehm, J. W. Bennett, M. R. Schoenberg, I. Grinberg, A. M. Rappe, J. Chem. Phys. 2014, 140, 224703.

[38] J. B. Goodenough, Reports Prog. Phys. 2004, 67, 1915-1993. 
[39] H. Haschke, H. Nowotny, F. Benesovsky, Monatshefte für Chemie 1967, 98, 2157-2163.

[40] E. F. Bertaut, D. Fruchart, J. P. Bouchaud, R. Fruchart, Solid State Commun. 1968, 6, 251-256.

[41] D. Fruchart, E. Bertaut, F. Sayetat, M. Nasr Eddine, R. Fruchart, J. Senateur, Solid State Commun. 1970, 8, 91-99.

[42] T He, Q Huang, A. P. Ramirez, Y Wang, K. A. Regan, N Rogado, M. A. Hayward, M. K. Haas, J. S. Slusky, K Inumara, H. W. Zandbergen, N. P. Ong, R. J. Cava, Nature 2001, 411, 54-56.

[43] K. Takenaka, H. Takagi, Appl. Phys. Lett. 2005, 87, 261902.

[44] K. Kamishima, T. Goto, H. Nakagawa, N. Miura, M. Ohashi, N. Mori, T. Sasaki, T. Kanomata, Phys. Rev. B 2000, 63, 024426.

[45] F. Gäbler, W. Schnelle, A. Senyshyn, R. Niewa, Solid State Sci. 2008, 10, 1910-1915.

[46] B. S. Wang, P. Tong, Y. P. Sun, W. Tang, L. J. Li, X. B. Zhu, Z. R. Yang, W. H. Song, Phys. B 2010, 405, 2427-2430.

[47] E. V. Gomonaj, V. A. L'Vov, Phase Transitions 1992, 40, 225-237.

[48] Y. Sun, X.-Q. Chen, S. Yunoki, D. Li, Y. Li, Phys. Rev. Lett. 2010, 105, 216406.

[49] J. Nuss, C. Mühle, K. Hayama, V. Abdolazimi, H. Takagi, Acta Crystallogr. Sect. B Struct. Sci. Cryst. Eng. Mater 2015, 71, 300-312.

[50] H. Fang, P. Jena, J. Mater. Chem. A 2016, 4, 4728-4737.

[51] H. Fang, P. Jena, Proc. Natl. Acad. Sci. U.S.A. 2017, 114, 11046-11051.

[52] M. G. André, Compt. Rend. 1883, 96, 435-437.

[53] H. L. Wells, W. R. Johnston, Am. J. Sci. 1893, 46, 25-34.

[54] C. D. Raagland, Some double halides of cadmium with the Methylamines and Tetramethylammoniu: A dissertation ... Easton PA, Chemical Publishing Company, 1897, pp. 1-35.

[55] H. Topsøe, Zeitschrift für Krist. 1884, 8, 246-320.

[56] E. Schmidt, H. Preßler, Eur. J. Org. Chem. 1883, 217, 287-306.

[57] E. von Federow, Zeitschrift für Krist. 1904, 38, 321-490.

[58] R. W. G. Wyckoff, Am. J. Sci. 1928, s5-16, 349-359.

[59] S. N. Ruddlesden, P. Popper, Acta Crystallogr. 1957, 10, 538-539.

[60] J. P. Steadman, R. D. Willett, Inorganica Chim. Acta 1970, 4, 367-371.

[61] H Arend, W Huber, F. H. Mischgofsky, G. K. Richter-Van Leeuwen, J. Cryst. Growth 1978, 43, 213-223.

[62] J. Gebhardt, Y. Kim, A. M. Rappe, J. Phys. Chem. C 2017, 121, 65696574 .

[63] B. Saparov, D. B. Mitzi, Chem. Rev. 2016, 116, 4558-4596.

[64] Z. Cheng, J. Lin, CrystEngComm 2010, 12, 2646-2662.

[65] D. B. Mitzi, C. D. Dimitrakopoulos, L. L. Kosbar, Chem. Mater. 2001, 13, 3728-3740. 
[66] D. Weber, Z. Naturforsch. 1978, 33B, 862-865.

[67] NREL, https://www.nrel.gov/pv/assets/pdfs/pv-efficiencies-07-17-2018.pdf, access date 01.09.2018.

[68] R. Azumi, K. Honda, M. Goto, J. Akimoto, Y. Oosawa, H. Tachibana, M. Tanaka, M. Matsumoto, Mol. Cryst. Liq. Cryst. Sci. Technol. Sect. A. Mol. Cryst. Liq. Cryst. 1996, 276, 237-243.

[69] G. Niu, X. Guo, L. Wang, J. Mater. Chem. A 2015, 3, 8970-8980.

[70] C. Grätzel, S. M. Zakeeruddin, Mater. Today 2013, 16, 11-18.

[71] Q. Chen, N. De Marco, Y. Yang, T. B. Song, C. C. Chen, H. Zhao, Z. Hong, H. Zhou, Y. Yang, Nano Today 2015, 10, 355-396.

[72] Y. Zhao, K. Zhu, Chem. Soc. Rev. 2016, 45, 655-689.

[73] J. M. Ball, A. Petrozza, Nat. Energy 2016, 1, 16149.

[74] N.-G. Park, M. Grätzel, T. Miyasaka, K. Zhu, K. Emery, Nat. Energy 2016, 1, 16152 .

[75] B. R. Sutherland, E. H. Sargent, Nat. Photonics 2016, 10, 295-302.

[76] T. M. Brenner, D. A. Egger, L. Kronik, G. Hodes, D. Cahen, Nat. Rev. Mater. 2016, 1, 15007.

[77] J. Huang, Y. Yuan, Y. Shao, Y. Yan, Nat. Rev. Mater. 2017, 2, 17042.

[78] M. A. Green, A. Ho-Baillie, ACS Energy Lett. 2017, 2, 822-830.

[79] J. Berry, T. Buonassisi, D. A. Egger, G. Hodes, L. Kronik, Y.-L. Loo, I. Lubomirsky, S. R. Marder, Y. Mastai, J. S. Miller, D. B. Mitzi, Y. Paz, A. M. Rappe, I. Riess, B. Rybtchinski, O. Stafsudd, V. Stevanovic, M. F. Toney, D. Zitoun, A. Kahn, D. Ginley, D. Cahen, Adv. Mater. 2015, 27, $5102-5112$.

[80] D. A. Egger, A. Bera, D. Cahen, G. Hodes, T. Kirchartz, L. Kronik, R. Lovrincic, A. M. Rappe, D. R. Reichman, O. Yaffe, Adv. Mater. 2018, 1800691, 1-11.

[81] W. Li, Z. Wang, F. Deschler, S. Gao, R. H. Friend, A. K. Cheetham, Nat. Rev. Mater. 2017, 2, 16099.

[82] Z. Shi, J. Guo, Y. Chen, Q. Li, Y. Pan, H. Zhang, Y. Xia, W. Huang, Adv. Mater. 2017, 29, 1605005.

[83] P.-O. Löwdin, J. Chem. Phys. 1950, 18, 365-375.

[84] R. S. Mulliken, J. Chem. Phys. 1955, 23, 1833-1840.

[85] F. L. Hirshfeld, Theor. Chim. Acta 1977, 44, 129-138.

[86] R. F. W. Bader, Atoms in Molecules: A Quantum Theory, Clarendon Press, Oxford, 1994.

[87] L. Jiang, S. V. Levchenko, A. M. Rappe, Phys. Rev. Lett. 2012, 108, 166403.

[88] A. Landé, Z. Phys. 1920, 1, 191-197.

[89] J. A. Wasastjerna, Comm. Phys.-Math. Soc. Sci. Fenn. 1923, 1, 1-25.

[90] H. G. Grimm, H. Wolff, Z. Phys. Chem. 1926, 119, 254-274.

[91] L. Pauling, J. Am. Chem. Soc. 1927, 49, 765-790. 
[92] W. H. Zachariasen, Z. Krist. 1931, 80, 137-153.

[93] L. Ahrens, Geochim. Cosmochim. Acta 1952, 2, 155-169.

[94] R. D. Shannon, C. T. Prewitt, Acta Crystallogr. Sect. B Struct. Crystallogr. Cryst. Chem. 1969, B25, 925-946.

[95] R. D. Shannon, Acta Crystallogr. Sect. A Cryst. Phys. Diffr. Theor. Gen. Crystallogr. 1976, 32, 751-767.

[96] R. D. Shannon in Struct. Bond. Cryst. (Eds.: M. O'Keeffe, A. Navrotsky), Academic Press, New York, 1981, pp. 53-70.

[97] W. H. Baur, Crystallogr. Rev. 1987, 1, 59-83.

[98] W. Travis, E. N. K. Glover, H. Bronstein, D. O. Scanlon, R. G. Palgrave, Chem. Sci. 2016, \%, 4548-4556.

[99] G. Kieslich, S. Sun, A. K. Cheetham, Chem. Sci. 2014, 5, 4712-4715.

[100] G. Kieslich, S. Sun, A. K. Cheetham, Chem. Sci. 2015, 6, 3430-3433.

[101] M. R. Filip, G. E. Eperon, H. J. Snaith, F. Giustino, Nat. Commun. 2014, 5, 1-9.

[102] M. Becker, T. Klüner, M. Wark, Dalt. Trans. 2017, 46, 3500-3509.

[103] O. Knop, I. A. Oxton, M. Falk, Can. J. Chem. 1979, 404-423.

[104] J. Gebhardt, A. M. Rappe, Comput. Phys. Commun. 2018, Submitted.

[105] V. L. Miller, S. C. Tidrow, Integr. Ferroelectr. 2015, 166, 30-47.

[106] N. Allan, M. Dayer, D. Kulp, W. Mackrodt, J. Mater. Chem. 1991, 1, 1035-1039.

[107] H. Kronmüller, S. Parkin, Handbook of magnetism and advanced magnetic materials, 4th ed., (Ed.: Wiley-Blackwell), 2007.

[108] K. S. Aleksandrov, J. Bartolomé, Phase Transitions 2001, 74, 255-335.

[109] J. Gebhardt, A. M. Rappe, J. Phys. Chem. C 2018, 122, 13872-13883.

[110] O. Muller, R. Rustum, The major ternary structural families (Crystal chemistry of non-metallic materials), Springer-Verlag, New York, 1974.

[111] D. G. Pettifor, Solid State Commun. 1984, 51, 31-34.

[112] D. G. Pettifor, Mater. Sci. Technol. 1988, 4, 675-691.

[113] C. Li, K. C. K. Soh, P. Wu, J. Alloys Compd. 2004, 372, 40-48.

[114] G. S. Rohrer, Structure and Bonding in Crystalline Materials, Cambridge University Press, Cambridge, 2001.

[115] C. Li, X. Lu, W. Ding, L. Feng, Y. Gao, Z. Guo, Acta Crystallogr. Sect. B Struct. Sci. 2008, 64, 702-707.

[116] M. R. Filip, F. Giustino, J. Phys. Chem. C 2016, 120, 166-173.

[117] M. R. Filip, F. Giustino, Proc. Natl. Acad. Sci. 2018, 115, 5397-5402.

[118] N. L. Rosi, Science 2003, 300, 1127-1129.

[119] A. K. Cheetham, C. N. R. Rao, R. K. Feller, Chem. Commun. 2006, 0, 4780-4795.

[120] H. C. Zhou, J. R. Long, O. M. Yaghi, Chem. Rev. 2012, 112, 673-674. 
[121] D. Weber, Z. Naturforsch. 1978, 33B, 1443-1445.

[122] C. K. Møller, Nature 1958, 182, 1436.

[123] A. M. Raaen, I. Svare, M. Fibich, Phys. Scr. 1982, 25, 957-960.

[124] H. Fuess, M. Körfer, H. Arend, R. Kind, Solid State Commun. 1985, 56, 137-139.

[125] M. Couzi, A. Daoud, R. Perret, Phys. Stat. Sol. 1977, 41, 271-282.

[126] D. B. Mitzi, Prog. Inorg. Chem. 1999, 48, (Ed.: K. D. Karlin), 1-122.

[127] A. Kojima, K. Teshima, Y. Shirai, T. Miyasaka, J. Am. Chem. Soc. 2009, 131, 6050-6051.

[128] J.-H. Im, C.-R. Lee, J.-W. Lee, S.-W. Park, N.-G. Park, Nanoscale 2011, 3, 4088-4093.

[129] M. A. Green, Y. Hishikawa, E. D. Dunlop, D. H. Levi, J. Hohl-Ebinger, A. W. Y. Ho-Baillie, Prog. Photovolt. Res. Appl. 2018, 26, 427-436.

[130] W. S. Yang, J. H. Noh, N. J. Jeon, Y. C. Kim, S. Ryu, J. Seo, S. I. Seok, Science 2015, 348, 1234-1237.

[131] Oxford PV sets world record for perovskite solar cell, 2018.

[132] F. Chiarella, P. Ferro, F. Licci, M. Barra, M. Biasiucci, A. Cassinese, R. Vaglio, Appl. Phys. A Mater. Sci. Process. 2007, 86, 89-93.

[133] F. Hao, C. C. Stoumpos, D. H. Cao, R. P. Chang, M. G. Kanatzidis, Nat. Photonics 2014, 8, 489-494.

[134] F. Hao, C. C. Stoumpos, R. P. Chang, M. G. Kanatzidis, J. Am. Chem. Soc. 2014, 136, 8094-8099.

[135] N. K. Noel, S. D. Stranks, A. Abate, C. Wehrenfennig, S. Guarnera, A.-A. Haghighirad, A. Sadhanala, G. E. Eperon, S. K. Pathak, M. B. Johnston, A. Petrozza, L. M. Herz, H. J. Snaith, Energy Environ. Sci. 2014, 7, 3061-3068.

[136] M. Konstantakou, T. Stergiopoulos, J. Mater. Chem. A 2017, 5, 11518 11549.

[137] I. E. Castelli, J. M. García-Lastra, K. S. Thygesen, K. W. Jacobsen, APL Mater. 2014, 2, 081514.

[138] T. Nakajima, K. Sawada, J. Phys. Chem. Lett. 2017, 8, 4826-4831.

[139] C. Kim, T. D. Huan, S. Krishnan, R. Ramprasad, Sci. Data 2017, 4, $1-11$.

[140] J.-H. Im, J. Chung, S.-J. Kim, N.-G. Park, Nanoscale Res. Lett. 2012, 7, 353 .

[141] D. B. Mitzi, C. A. Feild, W. T. A. Harrison, A. M. Guloy, Nature 1994, 369, 467-469.

[142] B. J. Beberwyck, Y. Surendranath, A. P. Alivisatos, J. Phys. Chem. C 2013, 117, 19759-19770.

[143] J. Gopalakrishnan, Chem. Mater. 1995, 7, 1265-1275.

[144] The National Institute for Occupational Safety and Health (NIOSH), Lead, 2016. 
[145] I. C. Smith, E. T. Hoke, D. Solis-Ibarra, M. D. McGehee, H. I. Karunadasa, Angew. Chem. Int. Ed. 2014, 53, 11232-11235.

[146] L. N. Quan, M. Yuan, R. Comin, O. Voznyy, E. M. Beauregard, S. Hoogland, A. Buin, A. R. Kirmani, K. Zhao, A. Amassian, D. H. Kim, E. H. Sargent, J. Am. Chem. Soc. 2016, 138, 2649-2655.

[147] The National Institute for Occupational Safety and Health (NIOSH), Thallium, soluble compounds (as Tl), 2004.

[148] J. R. DiPalma, Emerg. Med. News 2001, 23, 16.

[149] B. Chabot, E. Parthé, Acta Crystallogr. Sect. B Struct. Crystallogr. Cryst. Chem. 1978, 34, 645-648.

[150] Y. N. Ivanov, A. A. Sukhovskii, V. Lisin, I. P. Aleksandrova, Inorg. Mater. 2011, 37, 623-627.

[151] A. J. Lehner, D. H. Fabini, H. A. Evans, C. A. Hébert, S. R. Smock, J. Hu, H. Wang, J. W. Zwanziger, M. L. Chabinyc, R. Seshadri, Chem. Mater. 2015, 27, 7137-7148.

[152] P Szklarz, A Pietraszko, R Jakubas, G Bator, P Zieliński, M Gałazka, J. Phys. Condens. Matter 2008, 20, 255221.

[153] S. Vasala, M. Karppinen, Prog. Solid State Chem. 2015, 43, 1-36.

[154] N. Kojima, Bull. Chem. Soc. Jpn. 2000, 73, 1445-1460.

[155] M. Retuerto, T. Emge, J. Hadermann, P. W. Stephens, M. R. Li, Z. P. Yin, M. Croft, A. Ignatov, S. J. Zhang, Z. Yuan, C. Jin, J. W. Simonson, M. C. Aronson, A. Pan, D. N. Basov, G. Kotliar, M. Greenblatt, Chem. Mater. 2013, 25, 4071-4079.

[156] N. Elliott, L. Pauling, J. Am. Chem. Soc. 1938, 60, 1846-1851.

[157] A. H. Slavney, T. Hu, A. M. Lindenberg, H. I. Karunadasa, J. Am. Chem. Soc. 2016, 138, 2138-2141.

[158] G. Volonakis, M. R. Filip, A. A. Haghighirad, N. Sakai, B. Wenger, H. J. Snaith, F. Giustino, J. Phys. Chem. Lett. 2016, 7, 1254-1259.

[159] G. Giorgi, K. Yamashita, Chem. Lett. 2015, 44, 826-828.

[160] F. Hong, B. Saparov, W. Meng, Z. Xiao, D. B. Mitzi, Y. Yan, J. Phys. Chem. C 2016, 120, 6435-6441.

[161] L. A. Paton, W. T. A. Harrison, Angew. Chemie - Int. Ed. 2010, 49, 7684-7687.

[162] Q. Pan, Z. B. Liu, Y. Y. Tang, P. F. Li, R. W. Ma, R. Y. Wei, Y. Zhang, Y. M. You, H. Y. Ye, R. G. Xiong, J. Am. Chem. Soc. 2017, 139, 39543957.

[163] W.-Y. Zhang, Y.-Y. Tang, P.-F. Li, P.-P. Shi, W.-Q. Liao, D.-W. Fu, H.-Y. Ye, Y. Zhang, R.-G. Xiong, J. Am. Chem. Soc. 2017, 139, 1089710902.

[164] W.-J. Xu, Z.-Y. Du, W.-X. Zhang, X.-M. Chen, CrystEngComm 2016 , $18,7915-7928$

[165] C. M. Kareis, S. H. Lapidus, J. H. Her, P. W. Stephens, J. S. Miller, J. Am. Chem. Soc. 2012, 134, 2246-2254. 
[166] J. H. Her, P. W. Stephens, C. M. Kareis, J. G. Moore, K. S. Min, J. W. Park, G. Bali, B. S. Kennon, J. S. Miller, Inorg. Chem. 2010, 49, 15241534.

[167] Y. Kawamoto, S. Yamashita, R. Yoshimoto, Y. Nakazawa, J. G. Dasilva, C. M. Kareis, J. S. Miller, J. Phys. Condens. Matter 2014, 26, 016001.

[168] G Thiele, D Messer, Z. anorg. allg. Chem. 1980, 464, 255-267.

[169] A. S. Antsyshkina, M. A. Porai-Koshits, V. N. Ostrikova, G. G. Sadikov, Koord. Khimiya 1983, 9, 855.

[170] Z. Duan, Z. Wang, S. Gao, Dalt. Trans. 2011, 40, 4465-4473.

[171] E. Eikeland, N. Lock, M. Filsø, M. Stingaciu, Y. Shen, J. Overgaard, B. B. Iversen, Inorg. Chem. 2014, 53, 10178-10188.

[172] V. Paredes-Garcia, A. Vega, M. A. Novak, M. G. F. Vaz, D. A. Souza, D. Venegas-Yazigi, E. Spodine, Inorg. Chem. 2009, 48, 4737-4742.

[173] Z. Wang, B. Zhang, K. Inoue, H. Fujiwara, T. Otsuka, H. Kobayashi, M. Kurmoo, Inorg. Chem. 2007, 46, 437-445.

[174] F. A. Mautner, H. Krischner, C. Kratky, Monats. Chem. 1988, 119, 1245-1249.

[175] J. M. Bermúdez-García, M. Sánchez-Andújar, M. A. Señarís-Rodríguez, J. Phys. Chem. Lett. 2017, 8, 4419-4423.

[176] Y. Wu, S. Shaker, F. Brivio, R. Murugavel, P. D. Bristowe, A. K. Cheetham, J. Am. Chem. Soc. 2017, 139, 16999-17002.

[177] P. Schouwink, M. B. Ley, A. Tissot, H. Hagemann, T. R. Jensen, u. Smrčok, R. Černý, Nat. Commun. 2014, 5, 1-10.

[178] Z. M. Jin, Y. J. Pan, X. F. Li, M. L. Hu, L. Shen, J. Mol. Struct. 2003, $660,67-72$.

[179] G. Feng, X. Jiang, W. Wei, P. Gong, L. Kang, Z. Li, Y. Li, X. Li, X. Wu, Z. Lin, W. Li, P. Lu, Dalt. Trans. 2016, 45, 4303-4308.

[180] C. A. Bremner, M. Simpson, W. T. Harrison, J. Am. Chem. Soc. 2002, 124, 10960-10961.

[181] G. Z. Liu, J. Zhang, L. Y. Wang, Snyth. React. Inorg. Met.-Org. Nano Met. Chem. 2011, 41, 1091-1094.

[182] B. P. Batail, C. Livage, S. S. P. Parkin, C. Coulon, J. D. Martin, E. Canadell, Angew. Chem. Int. Ed. Engl. 1991, 30, 1498-1500.

[183] A. Dhouib, K. Essalah, B. Tangour, M. Abderraba, Int. J. Quantum Chem. 2002, 87, 220-224.

[184] T. Hiramatsu, Y. Yoshida, G. Saito, A. Otsuka, H. Yamochi, Y. Shimizu, Y. Hattori, Y. Nakamura, H. Kishida, H. Ito, K. Kirakci, S. Cordier, C. Perrin, J. Mater. Chem. C 2015, 3, 11046-11054.

[185] J. Gebhardt, A. M. Rappe, ACS Energy Lett. 2017, 2, 2681-2685.

[186] J. Gebhardt, A. M. Rappe, J. Mater. Chem. A 2018, 6, 14560.

[187] Z. Wei, W. Q. Liao, Y. Y. Tang, P. F. Li, P. P. Shi, H. Cai, R. G. Xiong, J. Am. Chem. Soc. 2018, 140, 8110-8113. 